\title{
Behavioral intentions of technology teachers to implement an engineering- focused curriculum
}

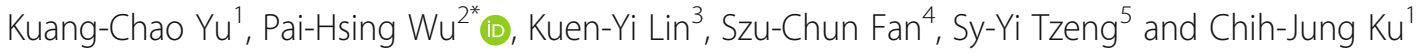

\begin{abstract}
Background: Teaching engineering at a high school level has been a subject of substantial concern during recent curriculum reforms. Many countries are increasingly including engineering-focused subjects in their technology curriculum guidelines. However, technology teachers face challenges regarding the optimal implementation of an engineering-focused curriculum. It is essential to understand technology teachers' perceptions of and behavior in classroom practices when teaching an engineering-focused curriculum. To explore the factors influencing the effective implementation of the curriculum, this study aimed to explore the association between technology teachers' perceptions regarding curriculum guidelines (i.e., perceived ease of use, perceived usefulness, and beliefs) and their behavioral intentions. In addition, this study explored how these perceptions change for teachers who participated in a professional development program (PDP) for teaching an engineering-focused curriculum compared with those who did not participate in the program (NoPDP).
\end{abstract}

Results: In this study, structural equation modeling was used to investigate factors potentially influencing teachers' behavioral intentions, including subjective norms and perceived behavioral control. The results showed that technology teachers' behavioral intentions were influenced by their perceptions of the curriculum's usefulness. Subjective norms and perceived behavioral control were also significant determinants of behavioral intentions. Moreover, the results differed between the two groups. Perceived usefulness had direct and indirect effects on the behavioral intentions of the PDP and NoPDP groups, respectively.

Conclusions: We constructed a model of technology teachers' behavioral intentions to implement an engineeringfocused curriculum and identified factors influencing technology teachers' behavioral intentions to implement an engineering-focused curriculum. Our conclusions are as follows: (1) the model was adequate for determining the factors influencing technology teachers' behavioral intentions; (2) in the PDP group, perceived usefulness, subjective norms, and perceived behavioral control were significantly associated with behavioral intentions; and (3) in the NoPDP group, perceived usefulness and perceived ease of use were associated with behavioral intentions and selfreported behavior only via the mediating factor of beliefs. The above influencing factors should be taken into account when planning professional development programs for pre- and in-service teachers, as these programs will have implications regarding the successful implementation of an engineering-focused curriculum.

Keywords: Engineering-focused curriculum, Structural equation modeling, Technology acceptance model, Technology teachers' behavioral intention model, Theory of planned behavior

\footnotetext{
* Correspondence: brain1124@gmail.com

${ }^{2}$ Research Center for Testing and Assessment, National Academy for

Educational Research, Taipei, Taiwan

Full list of author information is available at the end of the article
}

\section{Springer Open}

(- The Author(s). 2021 Open Access This article is licensed under a Creative Commons Attribution 4.0 International License, which permits use, sharing, adaptation, distribution and reproduction in any medium or format, as long as you give appropriate credit to the original author(s) and the source, provide a link to the Creative Commons licence, and indicate if changes were made. The images or other third party material in this article are included in the article's Creative Commons licence, unless indicated otherwise in a credit line to the material. If material is not included in the article's Creative Commons licence and your intended use is not permitted by statutory regulation or exceeds the permitted use, you will need to obtain permission directly from the copyright holder. To view a copy of this licence, visit http://creativecommons.org/licenses/by/4.0/. 


\section{Introduction}

The need for an integrated approach to science, technology, engineering, and mathematics (STEM) education has been increasingly acknowledged in recent years. To promote STEM education, the importance of teaching engineering at a high school level has been recognized in Taiwan's recent curriculum reform. Consequently, an engineering-focused curriculum using an engineering design process as the core component of the content has been mandated to be available to all high school students in the new national technology education curriculum of Taiwan starting in 2019 (Taiwan Ministry of Education [TMOE], 2018). The engineering-focused curriculum involves using the engineering design process to integrate STEM knowledge through participation in engineering projects. The engineering design process often includes defining the problem, identifying criteria and constraints, generating ideas, evaluating potential solutions, building and testing models or prototypes, and optimizing solutions (Lin et al., 2021; Merrill et al., 2008; NGSS Lead States, 2013).

The incorporation of engineering practices into high school technology education provides opportunities but also raises important questions about the preparation and ability of technology teachers. Technology teachers' knowledge, skills, and readiness to teach engineering have been found to be limited. Few teachers have taken engineering courses during preservice teacher preparation programs. Therefore, providing teacher professional development programs is urged to increase their expertise in teaching the engineering design process and developing STEM integration (TMOE, 2016). To that end, a professional development program (PDP) was developed and offered by the Ministry of Education of Taiwan in 2017 to enhance technology teachers' engineering knowledge, including content knowledge (CK) and pedagogical content knowledge (PCK), and allow them to effectively deliver an engineering-focused curriculum.

With the increasing emphasis on implementing an engineering-focused curriculum in K-12 classrooms, many researchers have identified some practical challenges or barriers, such as instructional materials, time for planning and implementing STEM curriculum, and administrative support, when implementing engineering activities within classrooms (Hammack \& Ivey, 2019; Yaşar et al., 2013). However, little research has been conducted to investigate teachers' behavioral intentions as they relate to teacher perceptions and beliefs about the curriculum. As teachers' prior views and experiences influence their STEM instruction (Christian et al., 2021; Margot \& Kettler, 2019), it is important to understand technology teachers' perceptions and actual classroom behavioral practices when teaching an engineering- focused curriculum. Therefore, it is essential to determine the factors that influence teachers' behavioral intentions (BI) with respect to implementing an engineering-focused curriculum. Such factors should be taken into account when planning professional development programs for pre- and in-service teachers, and these programs likely have implications regarding the successful implementation of the engineering-focused curriculum and achievement of the goals for STEM education (Kirchhoff \& Lawrenz, 2011).

This research applied a revised theory of planned behavior (TPB)-based model (Pynoo \& van Braak, 2014) and proposed the technology teachers' behavioral intention model (TTBIM). In our proposed model, teachers' self-reported behaviors (SRB) and BI to implement an engineering-focused curriculum are explored in terms of perceived ease of use (PEU), perceived usefulness (PU), beliefs (BF), subjective norms (SN), and perceived behavioral control (PBC). More specifically, this study investigated (1) whether the TTBIM can capture technology teachers' BI and (2) how the PDP influences technology teachers' BI. A detailed description of the definitions is provided in the Theoretical Basis section.

\section{Theoretical basis}

\section{Factors influencing the implementation of educational programs}

This study viewed the engineering-focused curriculum as a kind of educational innovation, which is a new program using different design thinking approaches for technology teachers. Some factors could influence teachers' implementation in using educational innovations. For example, Thibaut et al. (2018) indicated that teachers' attitudes positively affected their classroom practices in STEM courses. In addition, Yoon et al. (2014) pointed out that teachers' beliefs in their abilities positively affected students' learning of engineering. Moreover, Eccles and his colleagues proposed the EVT model, which emphasizes that the social expectations of an individual's perception will affect their beliefs and the individual's perception of the expectations of others will affect their perceptions of actual performance (Eccles et al., 1983, p. 85).

However, the relationships among technology teachers' belief factors that influence their actual behaviors are complex. Many researchers have investigated the influencing factors and proposed a potential model to illustrate the relationships that influence teachers' implementation of an innovative curriculum. On the basis of teachers' different characteristics, previous studies have proposed models to investigate and illustrate the relationships that influence the implementation of teaching practices. One such model, the theory of planned behavior (TPB), was proposed by Ajzen (1991), who assumed 
that teachers' actual behavior was associated with their behavioral intentions. Behavioral intentions refer to attitudes toward behavior, subjective norms, and perceived behavioral controls. Behavioral attitudes are derived from an individual's knowledge and overall attitude (Monroe et al., 2000), where an attitude comprises a set of values, feelings, and motives toward a particular environment (Chien et al., 2018). Regarding subjective norms, normative beliefs are mainly instilled through encouragement or pressure from society to embrace a particular viewpoint (Ajzen, 1985, 1991). Concerning perceived behavioral control, control beliefs influence an individual's likelihood of executing certain behaviors based on factors including the availability of resources or opportunities (Ajzen, 1985, 1991; Lin \& Williams, 2016).

Moreover, to determine how acceptable teachers' implementation of an innovative curriculum is, Davis et al. (1989) extended and modified the previous model and proposed the technology acceptance model (TAM). The TAM emphasizes perceived ease of use, perceived usefulness, attitudes toward use, behavioral intention to use, and then actual use. That is, teachers could accept a model according to whether it is easy to use and whether it can facilitate their teaching performance. These two types of perceptions of teachers would consequently influence their attitude toward use, the behavioral intention to use, and their actual use.

One's attitudes can include a person's beliefs, emotional reaction, and behavior (Fishbein \& Ajzen, 1975). In this study, we emphasize teachers' beliefs in teaching engineering-focused curriculum as their attitudes toward using the curriculum. Beliefs about instruction are mental constructions, which are central for teachers to effect change and improve instruction (Richardson, 1994). Consequently, teachers' beliefs about whether they have the knowledge, skills, and resources to successfully implement a new curriculum impact their success in teaching it (Carpenter et al., 1989; Rohaan et al., 2010; Van Haneghan et al., 2015). Through these beliefs, we can understand whether teachers' attitudes toward the use of the curriculum can help students apply STEM knowledge, solve problems, and understand engineering careers.

The teacher characteristics were summarized by Thibaut et al. (2018) based largely on the concept of behavioral attitudes proposed by Ajzen (1991), with less emphasis on SN and PBC. These two important factors, SN and PBC, were also considered by Eccles' EVT (1983). The TPB is not concerned with the contextual factors influencing teaching proposed by Thibaut et al. (2018). When the TPB is invoked to explain learning behavior, it is often assumed that the relationship between $\mathrm{BI}$ and actual behavior is significant. However, the results of several studies have not supported this supposition (Agudo-Peregrina et al., 2014; Pynoo \& van Braak, 2014). To resolve this problem, Pynoo and Van Braak (2014) integrated the technology acceptance model with the TPB to generate a more effective model for predicting educators' behaviors, as Fig. 1 shows.

To explore the technology teachers' behavioral intentions, the current study adopted Pynoo's integrated TAM/TPB model, using beliefs to replace attitude, and

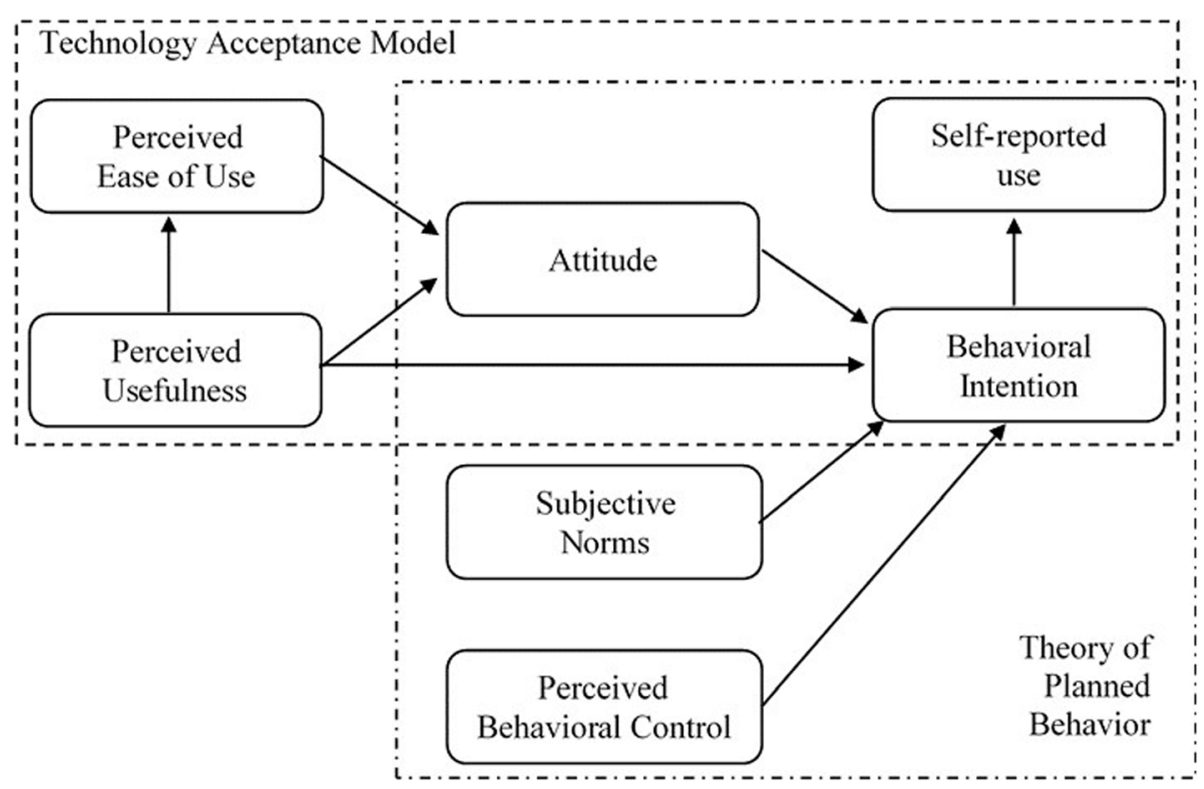

Fig. 1 Integrated TAM/TPB model. Adapted from Pynoo and van Braak (2014, p. 317) 
then transferred into the area of technology education (see Fig. 2). Table 1 presents the definitions of these constructs.

\section{Professional development programs for teaching an engineering-focused curriculum}

Shulman (1986) argued that teaching development programs should not only emphasize content knowledge and pedagogical knowledge but also consider pedagogical content knowledge. On that basis, various viewpoints on teachers' professional development have been adopted. Darling-Hammond and Baratz-Snowden (2007) identified three general areas of knowledge required to become an effective teacher: (a) knowledge of learners; (b) knowledge of the subject matter; and (c) knowledge of the content and learners to be taught. Following their review of earlier studies, Park and Oliver (2008) also identified four subdomains of teacher knowledge: (a) pedagogical knowledge; (b) subject matter knowledge; (c) pedagogical content knowledge; and (d) contextual knowledge. It was found that teachers' professional expertise was reflected in their knowledge of the content to be taught and their ability to teach it. In addition, Stein et al. (2007) proposed a professional development model for technology education emphasizing teachers' institutional, pedagogical, and field/disciplinary knowledge, as well as theoretical, practical, and reflective experience.

As engineering design activity is a pedagogical tool to extend and enhance learning in an engineering project (National Research Council, 2009), Hynes (2012) suggested that content knowledge and pedagogical content knowledge are central to teachers in an engineering course. In terms of designing an engineering PDP, Daugherty and Custer (2012) and McLaughlin (2002) stated that both CK and PCK should be considered. Additionally, Williams (2010) suggested that the core knowledge required for delivering an engineeringfocused curriculum, such as mechanical and electronic/ electrical engineering, includes knowledge of engineering design, process enterprises, the environment and the community, and systems and control.

The PDP for technology teachers was developed by the TMOE in 2017 based on the needs to improve teachers' engineering-related CK and PCK. The content of the PDP was developed in a three-stage research process that involves various methods, such as a literature review, expert interviews, and an online questionnaire survey. The first stage focused on a comparison of the content differences and PCK needed between the original curriculum and this new engineering-focused curriculum to determine the content to be addressed in the PDP. In the second stage, experts were interviewed to examine the adequacy of the content identified in the previous stage, which was further refined through rolling correction. The third stage was a questionnaire survey through which the opinions and suggestions of inservice teachers concerning the PDP were collected and assessed. More specifically, this PDP for technology teachers is geared toward engaging them in active experimentation and problem solving to become familiar with the methodology of engineering and the processes of engineering design. The PDP consists of three courses. The instructional strategy adopted for these courses is to organize the courses around practical project-based activities to assist teachers in implementing engineering design and STEM integration. The following is a brief description of the three courses (Fan \& Yu, 2017).

1. Mechatronics and electromechanical control

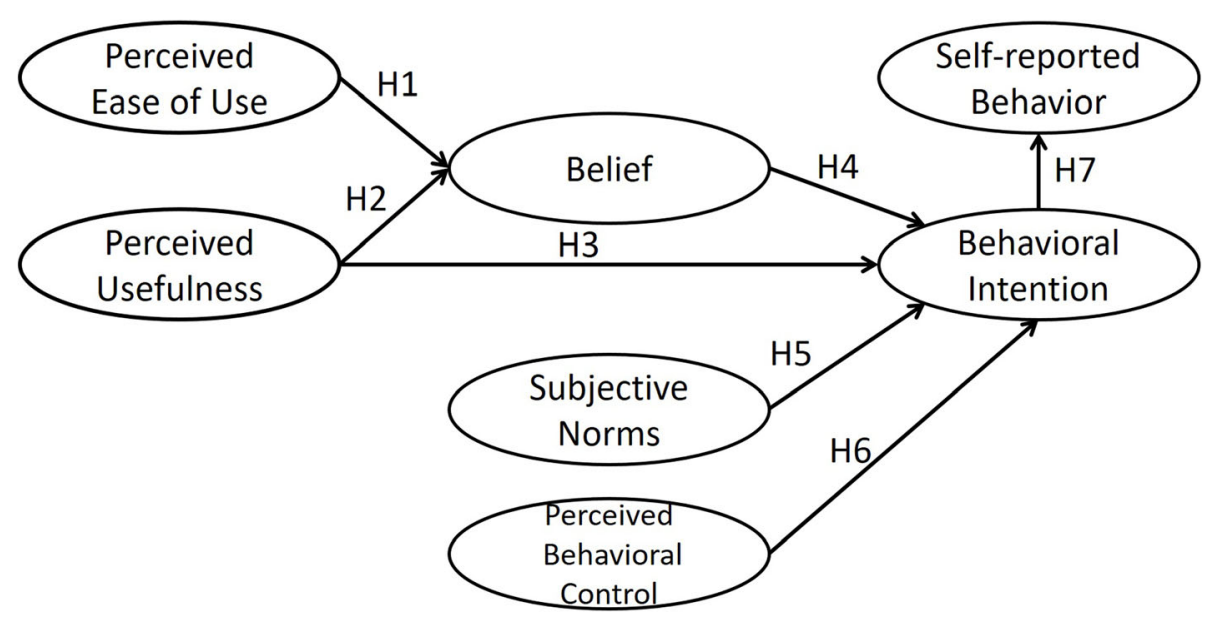

Fig. 2 Proposed model of technology teachers' behavioral intentions (TTBIM) 
Table 1 Operational definitions of the latent variables

\begin{tabular}{lll}
\hline Variable & Operational definition & No. of items \\
\hline Perceived ease of use (PEU) & Teachers' perception of the practicability of engineering-focused curriculum. \\
Perceived usefulness (PU) & Teachers' perception of the value of an engineering-focused curriculum. \\
Beliefs (BF) & Teachers' beliefs about teaching an engineering-focused curriculum. \\
Subjective norms (SN) & $\begin{array}{l}\text { Whether the positive or negative support given by important reference } \\
\text { groups will affect the teaching of an engineering-focused curriculum. } \\
\text { Perceived behavioral control (PBC) }\end{array}$ & $\begin{array}{l}\text { The ability of teachers to adjust or apply resources to implement an } \\
\text { engineering-focused curriculum. }\end{array}$ \\
Behavioral intentions (BI) & $\begin{array}{l}\text { Teachers' behavioral intentions regarding teaching an engineering-focused } \\
\text { Curriculum. }\end{array}$ \\
Self-reported behavior (SRB) & The self-reported behavior of technology teachers in implementing an \\
& engineering-focused curriculum in their school. \\
\hline
\end{tabular}

The course aims to strengthen teachers' CK and PCK concerning mechatronics and electromechanical control. The CK topics to be covered include electronic circuit design, circuit configuration, integration of transmission mechanisms and control systems, programming and applications of microcontroller systems, sensors and control applications, and equipment and techniques in electromechanical control. The PCK topics include theories of curriculum development, teaching material design, and instructional strategies to help teachers learn how related teaching skills can be applied. Figures 3, 4, and 5 present examples of the program implementation for these topics.

\section{Mechanism and structure}

The course aims to strengthen teachers' CK and PCK concerning the principles and applications of mechanical design. The CK topics to be covered include mechanical and structural design, engineering materials and their applications, product development and manufacturing, and applications of emerging technologies. PCK topics,

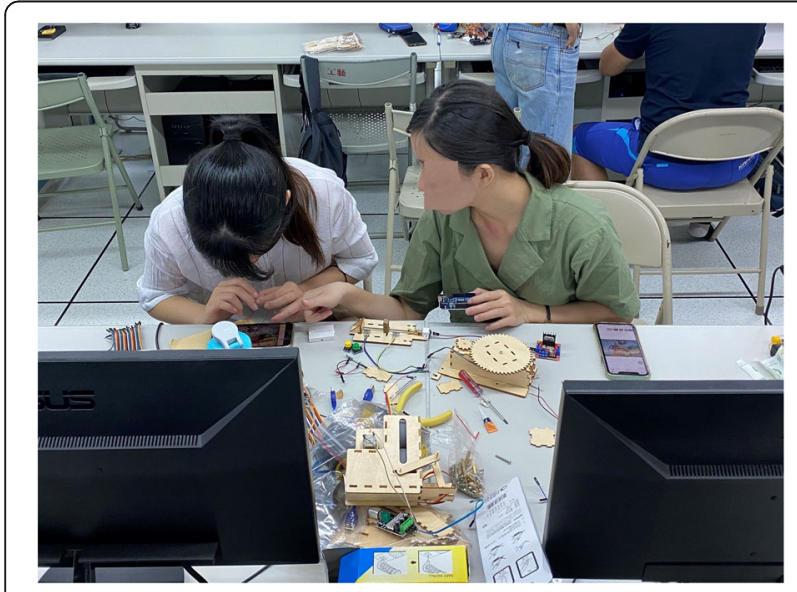

Fig. 3 Teachers discussed with each other during the PDP namely theories of curriculum development, teaching material design, and instructional strategies, are included to help teachers choose the appropriate teaching methods. Figures 6, 7, and 8 illustrate the implementation of the "Mechanism and Structure" program.

\section{Computer-aided design and manufacturing}

The course aims to strengthen teachers' CK and PCK concerning computer-aided design and manufacturing (CAD/CAM), enabling them to respond to students' needs. Key CK topics to be covered in the course include the basic principles, theoretical basis, and applications of CAD/CAM (e.g., 3D graphics techniques, computer numerical control, and $3 \mathrm{D}$ printing). The PCK topics include processes of technology design and engineering design to help teachers understand how knowledge of related techniques and equipment can be properly integrated into the classroom. Figures 9, 10, and 11 illustrate the implementation of the "computer-aided design and manufacturing" program.

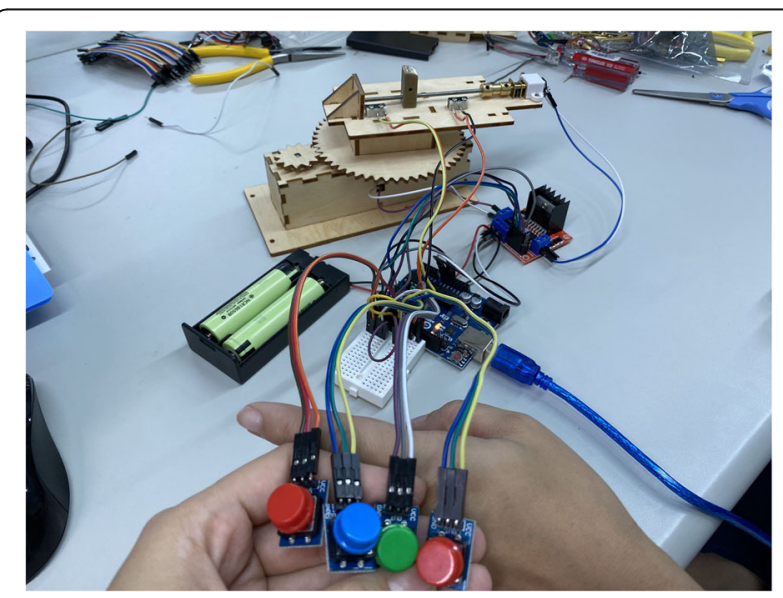

Fig. 4 Electronic circuit design and microcontroller systems applied 


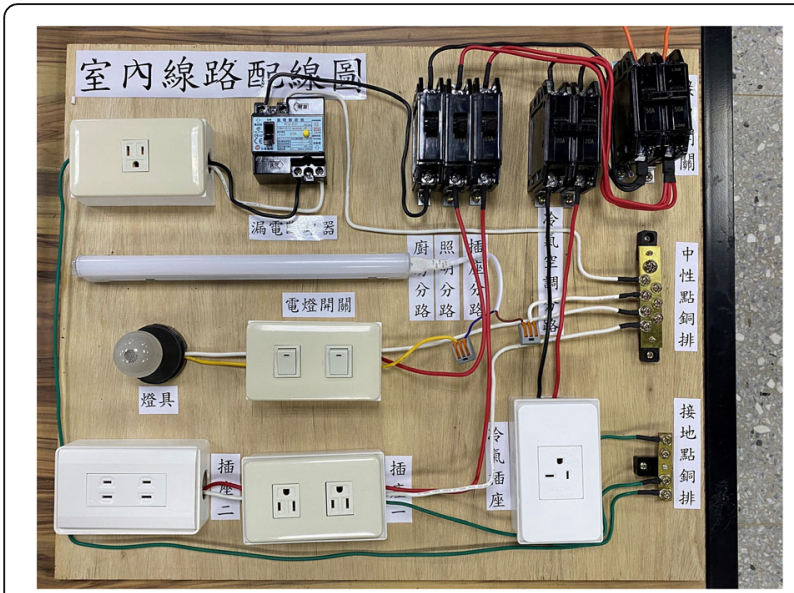

Fig. 5 Circuit design illustration

Despite the efforts to promote PDP for technology teachers in the last few years, little is known about how teachers value and practice the curriculum. Teachers, who are important to a student's talent development, hold prior views and experiences that influence their instruction (Margot \& Kettler, 2019). In this study, we address these issues by examining technology teachers' perceptions of and practices in an engineering-focused curriculum, drawing on a survey of technology teachers in high schools. In particular, we aim to understand factors that influence technology teachers' beliefs and behavior regarding the curriculum. We are also interested in investigating how technology teachers, with or without a PDP, teach an engineering-focused curriculum in technology classrooms.

\section{Research questions and proposed model}

The aim of the current study is to reveal and realize how technology teachers' actual usage of engineering-focused curriculum is based on their beliefs, perceptions of, and behavior while encountering the new curriculum guidelines.

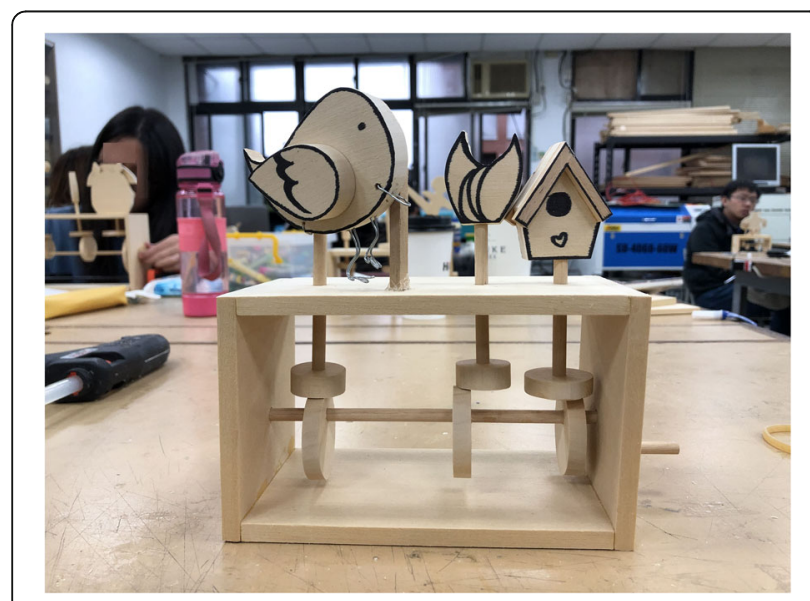

Fig. 6 Mechanical toy design

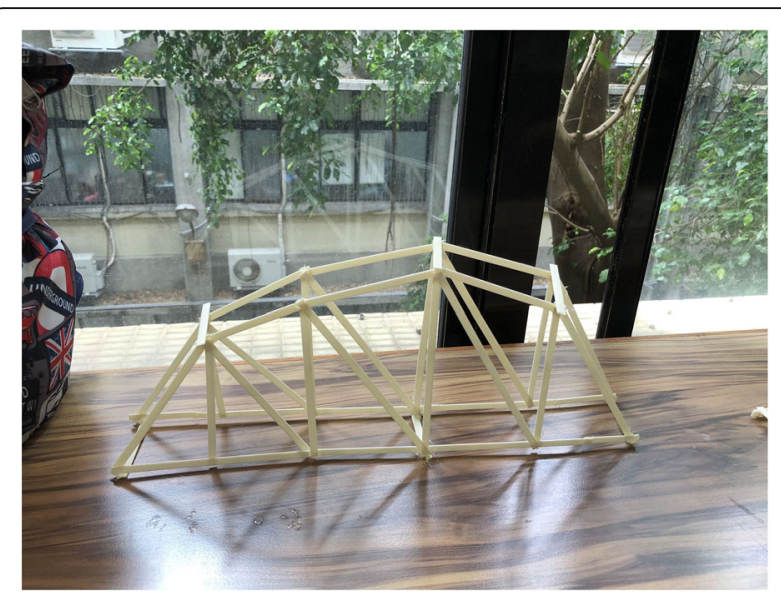

Fig. 7 Truss bridge structure modeling

Thus, the primary missions of this study are to examine whether the TTBIM captures technology teachers' BI and the effects of the PDP on teachers' BI. The key research questions are as follows:

1. What factors influence technology teachers' behavioral intentions with respect to implementing an engineering-focused curriculum?

2. Does the PDP affect technology teachers' behavioral intentions to implement an engineering-focused curriculum?

To answer the above questions, we enrolled 95 technology teachers in the present study. The central aim of this study is to determine whether our proposed model is useful for understanding teachers' BI to implement an engineering-focused curriculum and to quantify the associations among the model variables. The results should thus be instructive regarding technology teachers' BI to implement an engineering-focused curriculum.

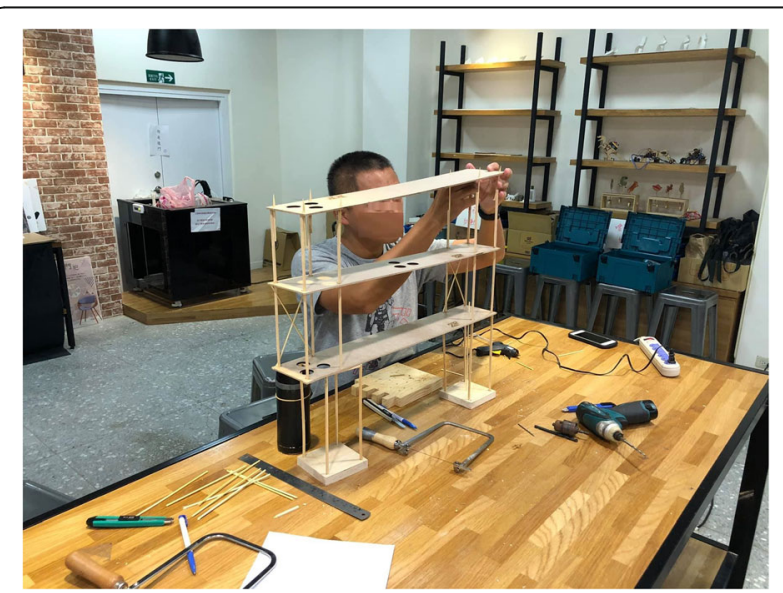

Fig. 8 Seismic structure application 


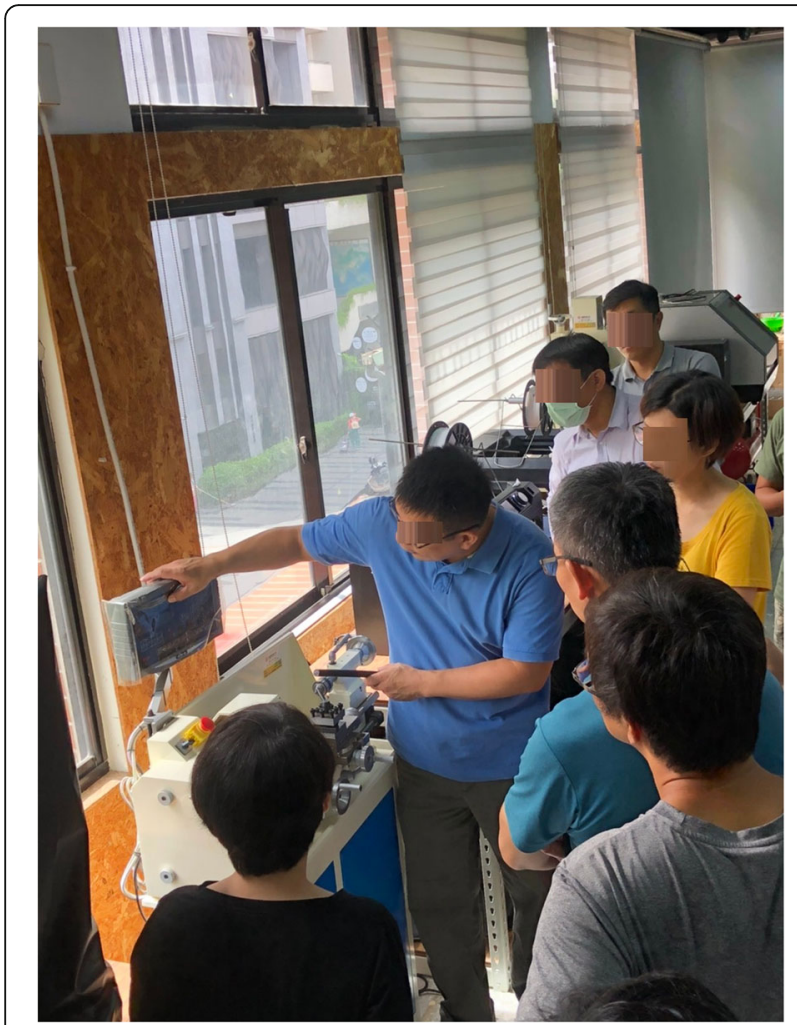

Fig. 9 Teachers discussed how to apply CAD/CAM in teaching

As described above, we proposed a model of technology teachers' BI (Fig. 2) and formulated the following research hypotheses: (1) PEU is associated with technology teachers' $\mathrm{BF}$ regarding an engineering-focused curriculum. (2) PU is associated with technology teachers' BF regarding an engineering-focused curriculum. (3) PEU is associated with technology teachers' BI. (4) BF is associated with technology teachers' BI. (5) SN are associated with technology teachers' BI. (6) PBC is associated with technology teachers' BI. (7) BI are associated with technology teachers' SRB.

\section{Methods}

\section{Sampling}

According to the database of the Technology Education Center, which is financially supported by the TMOE to provide curriculum and instruction assistance for technology teachers, there are 211 technology teachers in the email list. An online questionnaire was administered to the 211 technology teachers between August 1 and August 31, 2018, and 95 (45\%) valid questionnaires were obtained. Since only 95 technology teachers participated in our study, we estimated that the appropriate sample size in structural equation modeling should consider both the ratio of indicators to latent variables and the minimum effect in SEM at a given level of significance and power (Westland, 2010). According to Westland's

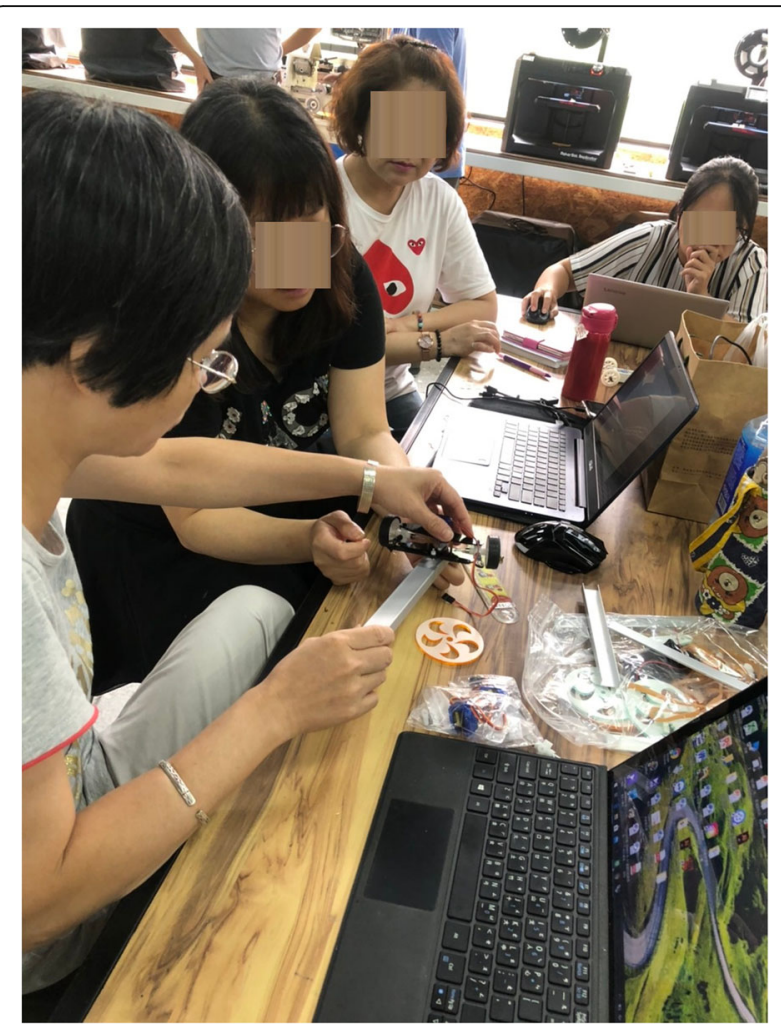

Fig. 10 Teachers discussed with each other during the PDP

suggestion, the suggested sample size was 88 for power $=.80, \alpha=.05$, and the medium effect size was $\left(R^{2}\right)=.15$, while the structural model had seven latent variables and 32 indicators. Since our sample size was slightly greater than the suggested number, our data had the

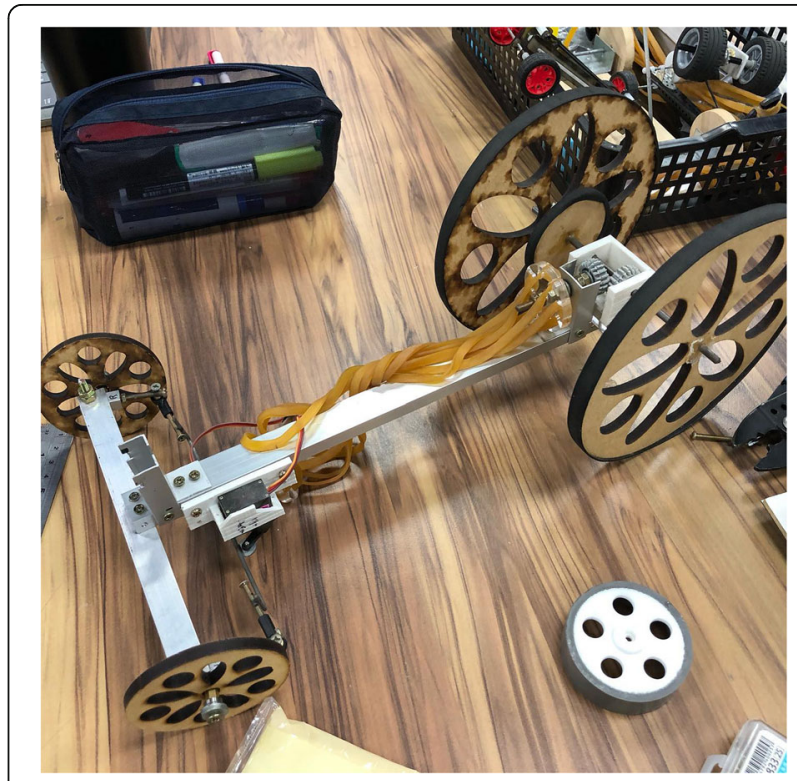

Fig. 11 Product design through CAD/CAM 
minimum level of effectiveness to evaluate the structural relationships among the variables.

The respondents were divided into two groups. Teachers in the first group had participated in the PDP (PDP group), while the other group included teachers who had not participated in the PDP (NoPDP group). The PDP group and NoPDP groups comprised 37 and 58 teachers, respectively. As shown in Table 2, the participating teachers were approximately three to one in terms of gender (75\% male and 25\% female), had an average of 12 teaching hours per week (range $0-26 \mathrm{~h}$ ), and came from three types of schools (64.2\% senior high school, $6.3 \%$ comprehensive high school, and 29.5\% high school).

\section{Measures}

The survey questionnaire included 32 items, including 5 on PEU, 4 on PU, 3 on BF, 4 on SN, 6 on PBC, 5 on BI, and 5 on SRB. Table 1 lists the latent variables in this study. Each questionnaire item was scored on a fivepoint Likert scale ranging from (1) strongly disagree to (5) strongly agree. Appendix 1 provides a more detailed description of the questionnaire, the content of which was examined by three technology and engineering education professors and three senior high school technology and engineering teachers. Cronbach's $\alpha$ for each scale ranged from .83 to .94 , and Cronbach's $\alpha$ for all 32 items was .96, indicating high internal consistency.

\section{Data analysis}

A two-step modeling approach (Anderson \& Gerbing, 1988) was adopted to test our hypothesized model. In the first step, confirmatory factor analysis (CFA) was employed to examine the construct validity of our model and investigate whether the questionnaire items represented the latent variables well. Based on the recommendations of earlier studies (Bagozzi \& Yi, 1988; Comrey \& Lee, 1992; Fornell, 1982; Harrington, 2008),

Table 2 The demographics of all participants

\begin{tabular}{lll}
\hline Items & $\boldsymbol{N}$ & Percentage \\
\hline Gender & 71 & $74.7 \%$ \\
Male & 24 & $25.3 \%$ \\
Female & & \\
Teaching hours & 20 & $21.1 \%$ \\
$0-5$ h & 24 & $25.2 \%$ \\
$6-10$ h & 9 & $9.5 \%$ \\
$11-15$ h & 42 & $44.2 \%$ \\
16 hours or above & & \\
School types & 61 & $64.2 \%$ \\
Senior high school (10-12) & 6 & $6.3 \%$ \\
Comprehensive high school (10-12) & 28 & $29.5 \%$ \\
High school (7-12) &
\end{tabular}

several validity criteria were utilized. For example, the factor loading should be greater than 0.55 , the coefficient of composite reliability (CR) should be greater than .60 , and the average variance extracted (AVE) for each latent variable should be at least 0.50 .

After determining the validity of our model, the relationships among the latent variables were tested using structural equation modeling. Goodness of fit was evaluated using measures recommended by earlier studies, including the chisquare to degree of freedom ratio $\left(\frac{X 2}{d f}\right)$, the root mean square error of approximation (RMSEA), the standardized root mean square residual (SRMR), and the comparative fit index (CFI). The chi-square ratio represents the obtained value of the chi-square under the degrees of freedom. The RMSE indicates whether our empirical model can fully represent the covariance of the whole population; the SRMR indicates the difference in the covariance residuals between the observed and predicted covariance; and the CFI indicates the relative improvement in the fit of our empirical model compared with a statistical baseline model (null model). The current study adopted the general rules for these indices, which include a standardized root mean square residual (SRMR) below 0.08 , a root mean square error of approximation (RMSEA) below 0.10, a comparative fit index (CFI) above 0.95 , and a chi-square to degrees of freedom ratio $\left(\frac{X 2}{d f}\right)$ below 3 (Bentler, 1990; Bowen \& Guo, 2011; Chen et al., 2008; Schreiber et al., 2006).

\section{Results}

\section{Descriptive statistics and correlation results}

The average scores for all questionnaire items ranged from 3.26 to 4.46 (Appendix 2). These average scores indicate that all of the questionnaires had a positive response. Moreover, Appendix 2 shows that all of the latent variables passed the normality test (i.e., an absolute kurtosis index less than 10 and an absolute skew index less than 3), as suggested by Kline (2011, p. 63). Therefore, the maximum likelihood (ML) estimation method was adapted to estimate the parameters of the structural equation (Bollen, 1989). Correlations among the items were also examined; in most cases, the correlations were significant (Appendix 3). We also examined the reliability of the 32 items (Appendix 4). The initial Cronbach's $\alpha$ values, provided above, indicated that the reliability of our instrument was acceptable (Cronbach, 1951); nevertheless, upon consideration of these values together with the correlation results, six items were removed due to low convergence and low internal consistency (i.e., PEU1, PU4, BF3, PBC3, BI1, and SRB1). Furthermore, the latent variable of BF had only two indicators after delimiting the inconsistency indicators. Bagozzi and Yi's model assessment study (1988) suggested the number of constructs and emphasized the constructs' internal consistency. That is, two indicators are acceptable if they have a high level of internal 
consistency in representing their constructs. Following Bagozzi and Yi's general rule, many empirical studies also examine structural relationships by adopting two indicators, such as the structural model of Kaiser et al. (2015) and Chao (2012). Thus, the internal inconsistency was recalculated, and the new values of Cronbach's $\alpha$ ranged from .84 to .96 (Appendix 4). The final questionnaire included 26 items, on which the latent variables in the TTBIM were based.

\section{Confirmatory factor analysis}

The CFA technique was used to confirm the convergent and discriminant validity of the seven latent variables (i.e., PEU, $\mathrm{PU}, \mathrm{BF}, \mathrm{SN}, \mathrm{PBC}, \mathrm{PBC}, \mathrm{BI}$, and SRB). Table 3 shows the standardized factor loading and residual estimates of the items for each latent variable in both the initial and final models.

The fit indices derived from the CFA confirmed that the final model had an adequate overall model-data fit.
Although the chi-square test showed a significant discrepancy in the data fit for the final model $\left(x^{2}=443.86, d f=\right.$ $278, p<.001)$, the $\frac{X 2}{d f}$ was below $3(1.60)$, suggesting a good fit. This was supported by the other indices (RMSEA = $0.080<0.10$, SRMR $=0.065<0.08$, and CFI $=0.97>0.95$ ).

The AVEs of the latent variables ranged from 0.69 to 0.87 (column 6 on Table 3), much higher than the cutoff value of 0.5 (Fornell \& Larcker, 1981). Thus, the AVE and $C R$ values indicated that the convergent validity of the latent variables was acceptable. Furthermore, the square roots of the AVEs were calculated to estimate the discriminant validity. Table 4 shows that all of the square root values were greater than those of the correlations between each pair of latent variables, thus confirming the variables' good discriminant validity. In particular, the two indicators of beliefs were strongly associated with technology teachers' beliefs rather than

Table 3 Statistics for the latent variables

\begin{tabular}{|c|c|c|c|c|c|}
\hline Latent variable & Item & Standardized factor loading (SE) & Residuals & $\mathrm{CR}$ & AVE \\
\hline \multirow[t]{4}{*}{ Perceived ease of use (PEU) } & PEU2 & $0.62^{\mathrm{a}}$ & 0.62 & .92 & 0.74 \\
\hline & PEU3 & $0.94(0.19)^{* * *}$ & 0.11 & & \\
\hline & PEU4 & $0.96(0.19)^{* * *}$ & 0.08 & & \\
\hline & PEU5 & $0.87(0.19)^{* * *}$ & 0.24 & & \\
\hline \multirow[t]{3}{*}{ Perceived usefulness (PU) } & PU1 & $0.86^{\mathrm{a}}$ & 0.27 & .93 & 0.81 \\
\hline & PU2 & $0.95(0.08)^{* * *}$ & 0.09 & & \\
\hline & PU3 & $0.89(0.09)^{* * *}$ & 0.22 & & \\
\hline \multirow[t]{2}{*}{ Beliefs (BF) } & BF1 & $0.84^{\mathrm{a}}$ & 0.29 & .84 & 0.73 \\
\hline & $\mathrm{BF} 2$ & $0.87(0.10)^{* * *}$ & 0.25 & & \\
\hline \multirow[t]{4}{*}{ Subjective norms (SN) } & SN1 & $0.79^{\mathrm{a}}$ & 0.38 & .90 & 0.69 \\
\hline & SN2 & $0.89(0.12)^{* * *}$ & 0.22 & & \\
\hline & SN3 & $0.79(0.13)^{* * *}$ & 0.37 & & \\
\hline & SN4 & $0.85(0.13)^{* * *}$ & 0.28 & & \\
\hline \multirow[t]{5}{*}{ Perceived behavioral control (PBC) } & PBC1 & $0.84^{\mathrm{a}}$ & 0.30 & .92 & 0.71 \\
\hline & PBC2 & $0.85(0.10)^{* * *}$ & 0.27 & & \\
\hline & PBC4 & $0.88(0.10)^{* * *}$ & 0.23 & & \\
\hline & PBC5 & $0.85(0.10)^{* * *}$ & 0.27 & & \\
\hline & PBC6 & $0.79(0.10)^{* * *}$ & 0.38 & & \\
\hline \multirow[t]{4}{*}{ Behavioral intentions (BI) } & $\mathrm{B} / 2$ & $0.91^{\mathrm{a}}$ & 0.17 & .96 & 0.85 \\
\hline & $\mathrm{BI} 3$ & $0.96(0.06)^{* * *}$ & 0.08 & & \\
\hline & $\mathrm{B} \mid 4$ & $0.95(0.06)^{* * *}$ & 0.09 & & \\
\hline & $\mathrm{BI} 5$ & $0.86(0.08)^{* * *}$ & 0.25 & & \\
\hline \multirow[t]{4}{*}{ Self-reported behavior (SRB) } & SRB2 & $0.85^{\mathrm{a}}$ & 0.10 & .96 & 0.87 \\
\hline & SRB3 & $0.92(0.05)^{* * *}$ & 0.15 & & \\
\hline & SRB4 & $0.98(0.04)^{* * *}$ & 0.03 & & \\
\hline & SRB5 & $0.88(0.06)^{* * *}$ & 0.23 & & \\
\hline
\end{tabular}

$C R$ composite reliability, AVE average variance extracted

${ }^{a}$ The factor loading was not estimated because the first item served as the reference value for estimation of the loading of the other items onto the same variable ${ }^{* * *} p<.001$ 
Table 4 Discriminant validity of the measurement model

\begin{tabular}{|c|c|c|c|c|c|c|c|}
\hline Latent variable & PEU & PU & $\mathrm{BF}$ & SN & PBC & BI & SRB \\
\hline Perceived ease of use (PEU) & $(0.86)^{a}$ & & & & & & \\
\hline Perceived usefulness (PU) & $0.53^{\mathrm{b}}$ & $(0.90)$ & & & & & \\
\hline Beliefs (BF) & 0.56 & 0.78 & $(0.85)$ & & & & \\
\hline Subjective norms (SN) & 0.49 & 0.50 & 0.57 & $(0.83)$ & & & \\
\hline Perceived behavioral control (PBC) & 0.82 & 0.49 & 0.60 & 0.62 & $(0.84)$ & & \\
\hline Behavioral intentions (BI) & 0.67 & 0.76 & 0.77 & 0.70 & 0.77 & $(0.92)$ & \\
\hline Self-reported behavior (SRB) & 0.46 & 0.38 & 0.41 & 0.35 & 0.49 & 0.55 & $(0.93)$ \\
\hline
\end{tabular}

avalues along the diagonal in parentheses are the square roots of the average variance extracted (AVE)

${ }^{b}$ Values along the off-diagonal are the correlations between the latent variables

other latent variables, as the fourth column shows that the correlation between beliefs and other variables ranged from 0.41 to 0.77 , which is smaller than 0.85 .

\section{Structural modeling}

In the second phase of our analysis, the structural relationships illustrated in Fig. 1 were examined, and fit indices were derived. The $\frac{\chi^{2}}{d f}$ was 1.58 (below 3), and the other fit indices indicated that our structural model had a good overall fit with the data (RMSEA $=0.078[<0.10]$, SRMR $=0.073[<0.08]$, and CFI $=0.97[>0.95])$. The model shown in Fig. 12 was thus adequate to describe the structural relationships among the latent variables.

\section{Behavioral intention model}

Our main aim was to determine the factors influencing technology teachers' BI with respect to implementing the engineering-focused curriculum. As shown in Fig. 12, BF was directly influenced by PEU $(\beta=.21, p<.05)$ and PU $(\beta=.68, p<.001)$. BF had a nonsignificant effect on BI $(\beta=.17$, ns.). In contrast, BI was significantly associated with PU $(\beta=.34, p<.01)$, SN $(\beta=.22, p<$ $.01)$, and PBC $(\beta=.37, p<.001)$. Finally, SRB was significantly influenced by BI $(\gamma=.55, p<.001)$.

Furthermore, $30.25 \%$ of the variance in SRB could be explained by BI. On the other hand, PU, SN, and PBC explained $11.34 \%, 4.84 \%$, and $13.69 \%$ of the variance in BI, respectively. Then, PEU and PU explained $4.41 \%$ and $46.24 \%$ of the variance in BF, respectively.

Table 5 shows the direct, indirect, and overall effects of the latent variables on BI and SRB. BI was associated with the overall effects of $\mathrm{PU}(0.45, p<.001)$, SN $(0.22$, $p<.01)$, and $\mathrm{PBC}(0.37, p<.001)$. No variable had a significant indirect effect on $\mathrm{BI}$, although $\mathrm{PU}$ had a direct effect $(0.34, p<.01)$. This result confirmed that PU exerts an important influence on teachers' BI with respect to implementing the curriculum.

The technology teachers' SRB regarding the curriculum was associated not only with BI (overall effect = $0.55, p<.05)$ but also with PU, SN, and PBC through an indirect pathway $(0.25, p<.01 ; 0.12, p<.05$; and $0.20, p$ $<.05$, respectively). The effects of BF and PEU on SRB were nonsignificant.

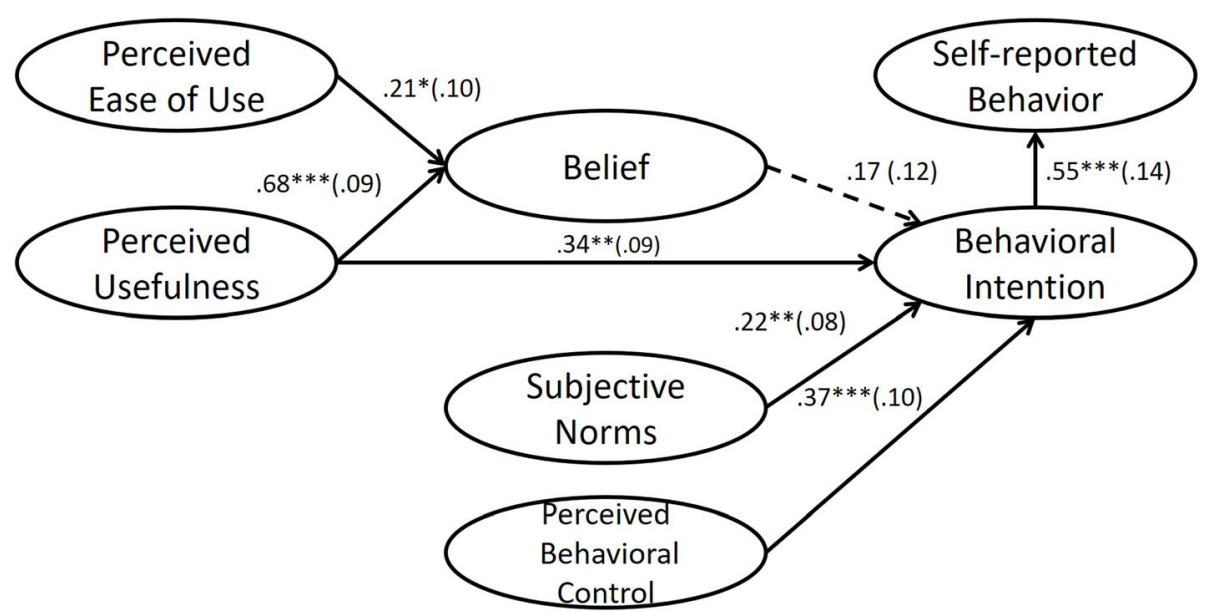

Fig. 12 The final TTBIM was based on the questionnaire data from 95 respondents. Solid lines indicate significant associations; dotted lines indicate nonsignificant associations. Arrows indicate the direction of the relationships. Figures in parentheses represent the standard error (SE). ${ }^{* * *} p<.001 ;{ }^{* *} p<.01 ;{ }^{*} p<.05$ 
Table 5 Direct, indirect, and overall effects of the latent variables on BI and SRB

\begin{tabular}{|c|c|c|c|c|c|c|}
\hline Variable & PEU & PU & $\mathrm{BF}$ & SN & PBC & $\mathrm{BI}$ \\
\hline \multicolumn{7}{|l|}{ on $\mathrm{Bl}$} \\
\hline Direct effect & - & $0.34(.06)^{* * *}$ & $0.17(.12)$ & $0.22(.08)^{* *}$ & $0.37(.10)^{* * *}$ & - \\
\hline Indirect effect & $0.04(.03)$ & $0.11(.07)$ & - & - & - & - \\
\hline Overall effect & $0.04(.03)$ & $0.45(.06)^{* * *}$ & $0.17(.12)$ & $0.22(.08)^{* *}$ & $0.37(.10)^{* * *}$ & - \\
\hline \multicolumn{7}{|l|}{ on SRB } \\
\hline Direct effect & - & - & - & - & - & $0.55(.14)^{* * *}$ \\
\hline Indirect effect & $0.02(.03)$ & $0.25(.07)^{* * *}$ & $0.09(.10)$ & $0.12(.07)^{*}$ & $0.20(.09)^{* * *}$ & - \\
\hline Overall effect & $0.02(.03)$ & $0.25(.07)^{* * *}$ & $0.09(.10)$ & $0.12(.07)^{*}$ & $0.20(.09)^{* * *}$ & $0.55(.14)^{* * *}$ \\
\hline
\end{tabular}

$P E U$ perceived ease of use, $P U$ perceived usefulness, $B F$ beliefs, $S N$ subjective norms, $P B C$ perceived behavioral control, $B I$ behavioral intentions, SRB self-reported behavior

${ }^{*} p<.05 ;{ }^{* *} p<.01 ;{ }^{* * *} p<.001$

\section{Effect of the PDP on BI}

To address research question 2 , we devised a model to determine whether PDP participation influences the BI to implement the engineering-focused curriculum (Figs. 13 and 14).

In the PDP group, the associations of BI and PEU with BF were nonsignificant, while in the NoPDP group, the associations between PU and BI and between $\mathrm{SN}$ and $\mathrm{BI}$ were nonsignificant. In the NoPDP group, the effects of both PU and PEU on BI and SRB were mediated by BF.

Tables 6 and 7 show the direct, indirect, and overall effects of the latent variables on BI and SRB. In both groups, the overall effect of PU on BI was the largest among all variables $(0.49, p<.001$ in the PDP group; $0.34, p<.01$ in the NoPDP group). In the PDP group, PU had a nonsignificant indirect effect and a significant direct effect on $\mathrm{BI}$ (0.77, $p<.001)$. However, in the NoPDP group, PU had a significant indirect effect on BI $(0.28, p<.001)$ and a nonsignificant direct effect. BF mediated the effect of PU on $\mathrm{BI}$ in the NoPDP group. These results indicated that teachers who participated in the PDP may focus more on the usefulness of the curriculum.

As shown in Table 7, in the PDP group, PU, SN, PBC, and BI had significant overall effects on SRB $(0.34, p<$ $.01 ; 0.25, p<.05 ; 0.15, p<.05$; and $0.69, p<.001$, respectively). In the NoPDP group, only PU, PBC, and BF had significant overall effects on SRB $(0.14, p<.01 ; 0.17$, $p<.05$; and $0.19, p<.05$, respectively).

\section{Discussion}

The results indicate that three main factors influence technology teachers' $\mathrm{BI}$ to implement an engineering-focused curriculum: PBC, SN, and PU. Our results also revealed differences in the influencing factors between the two teacher groups. PU had a direct effect on BI in the PDP group, while its effect was mediated by BF in the NoPDP group. Meanwhile, SN had significant and nonsignificant effects on the BI of the PDP and NoPDP groups, respectively.

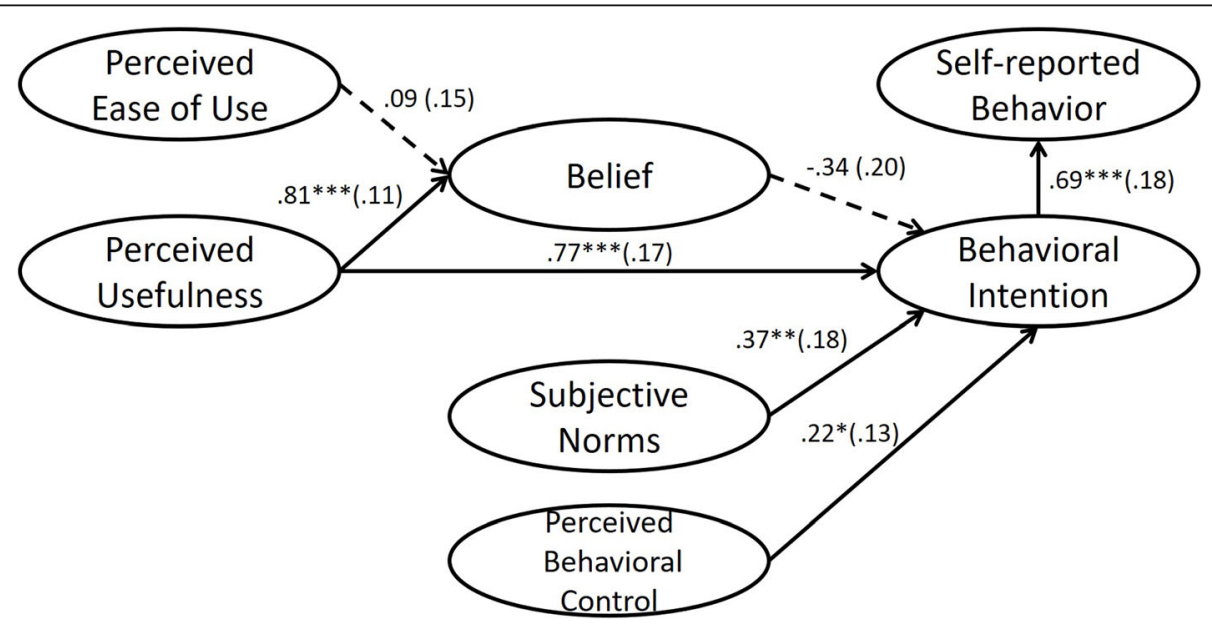

Fig. 13 The TTBIM for the PDP group $(n=37)$. Solid lines indicate significant associations, and dotted lines indicate nonsignificant associations. Arrows indicate the direction of the relationships. Figures in parentheses represent the standard error (SE). ${ }^{* *} p<.001 ;{ }^{* *} p<.01 ;{ }^{*} p<.05$ 


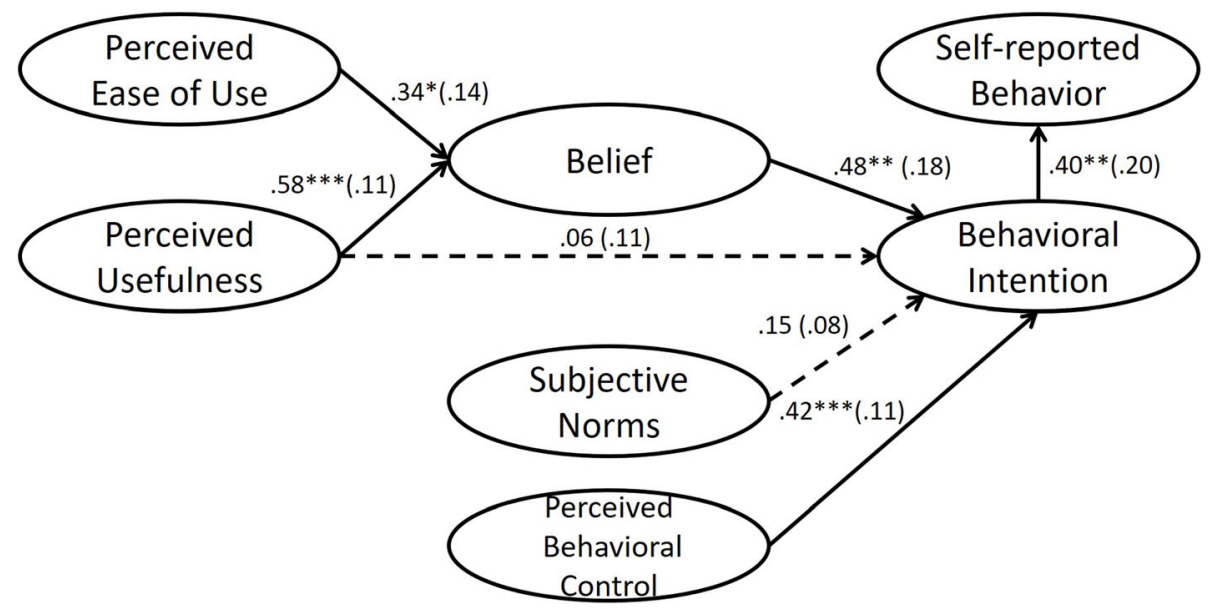

Fig. 14 The TTBIM for the NoPDP group $(n=58)$. Solid lines indicate significant associations, and dotted lines indicate nonsignificant associations. Arrows indicate the direction of the relationships. Figures in parentheses represent the standard error (SE). ${ }^{* *} p<.001 ;{ }^{* *} p<.01 ;{ }^{*} p<.05$

Interactions among perceived usefulness, attitude, and behavioral intentions

This research used Pynoo and van Braak's (2014) integrated TAM/TPB model to explain technology teachers' $\mathrm{BI}$ to implement an engineering-focused curriculum. The results indicated that our model was effective in explaining $\mathrm{BI}$, except for the BF factor. One possible reason for this result is that these teachers may lack confidence in their ability to implement the curriculum in terms of reflection and analysis skills (Daugherty \& Custer, 2012).

In our NoPDP group, PU affected BI only when BF was positive. This result is in line with a study postulating that the beliefs of teachers mediate their views, judgments, and actions (Nathan et al., 2010). However, BF regarding the engineering-focused curriculum had no influence on the BI of our PDP group, perhaps because the PDP group realized the value of an engineering-focused curriculum. This finding corroborates the result of an earlier study that found that the content of the curriculum and the teaching environment influence teachers' beliefs regarding teaching engineering
(Yoon et al., 2014); the more positive the teacher's BF, the greater their intention to implement the curriculum, even if their knowledge of it is low. However, when the teacher has attained a good understanding of the curriculum or comes to realize its usefulness, their BF will already likely be highly positive, such that BF will have less influence on their BI.

\section{SN affects teachers' BI}

For decades, research on teacher education concerned the effect of social norms on teachers' BI (Agudo-Peregrina et al., 2014; Pynoo \& van Braak, 2014). Some researchers found that SN had a weak influence on teachers' BI (Kriek \& Stols, 2010; Taylor \& Todd, 1995). In our study, SN did not affect the BI of the NoPDP group but did influence that of the PDP group. This finding is in line with the study of Teo (2011), who found that experienced teachers develop their teaching style via accommodation and assimilation of their prior experiences and knowledge. Thus, they may have a more fixed perspective on teaching, thereby relying less on outside resources or the suggestions of others. In the present

Table 6 Direct, indirect, and overall effects of the latent variables on BI by group

\begin{tabular}{|c|c|c|c|c|c|}
\hline Variable & PEU & PU & $\mathrm{BF}$ & SN & PBC \\
\hline \multicolumn{6}{|l|}{ PDP model } \\
\hline Direct effect & - & $0.77(.17)^{* * *}$ & $-0.34(.20)$ & $0.37(.18)^{* *}$ & $0.22(.13)^{*}$ \\
\hline Indirect effect & $-0.03(.06)$ & $-0.28(.13)$ & - & - & - \\
\hline Total effect & $-0.03(.06)$ & $0.49(.10)^{* * *}$ & $-0.34(.20)$ & $0.37(.18)^{* *}$ & $0.22(.13)^{*}$ \\
\hline \multicolumn{6}{|l|}{ NoPDP model } \\
\hline Direct effect & - & $0.06(.11)$ & $0.48(.18)^{*}$ & $0.15(.08)$ & $0.42(.11)^{* * *}$ \\
\hline Indirect effect & $0.16(.09)^{*}$ & $0.28(.10)^{*}$ & - & - & - \\
\hline Overall effect & $0.16(.09)$ & $0.34(.08)^{* *}$ & $0.48(.18)^{*}$ & $0.15(.08)$ & $0.42(.11)^{* * *}$ \\
\hline
\end{tabular}

PEU perceived ease of use, $P U$ perceived usefulness, $B F$ beliefs, $S N$ subjective norms, $P B C$ perceived behavioral control, $B I$ behavioral intentions, $S R B$ self-reported behavior

${ }^{*} p<.05 ;{ }^{* *} p<.01 ;{ }^{* * *} p<.001$ 
Table 7 Direct, indirect, and overall effects of the latent variables on SRB by group

\begin{tabular}{|c|c|c|c|c|c|c|}
\hline Variable & PEU & PU & $\mathrm{BF}$ & SN & PBC & BI \\
\hline \multicolumn{7}{|l|}{ PDP model } \\
\hline Direct effect & - & - & - & - & - & $0.69(.18)^{* * *}$ \\
\hline Indirect effect & $-0.02(.06)$ & $0.34(.12)^{* *}$ & $-0.24(.20)$ & $0.25(.19)^{*}$ & $0.15(.13)^{*}$ & - \\
\hline Total effect & $-0.02(.06)$ & $0.34(.12)^{* *}$ & $-0.24(.20)$ & $0.25(.19)^{*}$ & $0.15(.13)^{*}$ & $0.69(.18)^{* * *}$ \\
\hline \multicolumn{7}{|l|}{ NoPDP model } \\
\hline Direct effect & - & - & - & - & - & $0.40(.20)^{* *}$ \\
\hline Indirect effect & $0.07(.06)$ & $0.14(.07)^{*}$ & $0.19(.15)^{*}$ & $0.06(.06)$ & $0.17(.11)^{*}$ & - \\
\hline Overall effect & $0.07(.06)$ & $0.14(.07)^{* *}$ & $0.19(.15)^{*}$ & $0.06(.06)$ & $0.17(.11)^{*}$ & $0.40(.20)^{* *}$ \\
\hline
\end{tabular}

$P E U$ perceived ease of use, $P U$ perceived usefulness, $B F$ beliefs, $S N$ subjective norms, $P B C$ perceived behavioral control, $B I$ behavioral intentions, SRB self-reported behavior

${ }^{*} p<.05 ;{ }^{* *} p<.01 ;{ }^{* * *} p<.001$

study, NoPDP group teachers had more teaching hours (12.55 $\mathrm{h}$ per week) than PDP group teachers $(11.16 \mathrm{~h}$ per week); that is, NoPDP group teachers may nevertheless have had their own fixed perspective on teaching, thus preferring not to participate in the PDP. They may have believed that they could tailor their teaching based on students' interest in the engineering-focused curriculum and teach students through hands-on activities (see items PBC1 and PBC6 in Appendix 1). They may also have believed that they could deliver the engineering-focused curriculum simply by reading the curriculum guidelines, thus resisting the pressure from school administrators and educational authorities to participate in the PDP. These results indicate that for education reform and acceptance of the new engineering-focused curriculum, teachers' internal perspectives are more important than social expectations or norms.

\section{Conclusion and implications}

We constructed a model of technology teachers' BI to implement an engineering-focused curriculum. Our conclusions are as follows: (1) The model was adequate for determining the factors influencing technology teachers' BI. As the whole model (Fig. 12) shows that the effects of BF and PEU on SRB were nonsignificant, teachers may focus more on whether the curriculum facilitates their teaching and students' learning, as well as norms and support from administrators, parents, and society as a whole.

(2) In the PDP group, PU, SN, and PBC were significantly associated with BI. As the PDP model (Fig. 13) shows that $\mathrm{SN}$ was a significant factor in $\mathrm{BI}$ and SRB, adhering to SN may improve PDP group teachers' performance when they encounter new challenges.

(3) In the NoPDP group, PU and PEU were associated with BI and SRB only via BF mediation. The NoPDP model (Fig. 13) shows that PU and PEU only had indirect effects on BI and SRB. These results implied that beliefs about teaching the engineering-focused curriculum are dominant for NoPDP group teachers.
SN might be the most crucial factor in the decision of technology teachers to participate in the PDP, especially for teachers without a fixed perspective on teaching. To enhance teaching performance, educators and policymakers should target beginning teachers or young teachers without a fixed perspective on teaching and devise a PDP and provide environments that facilitate awareness among technology teachers of the usefulness of the engineering-focused curriculum. In addition to $\mathrm{SN}$, the results showed that PU influenced BI both directly and indirectly, likely because most technology teachers are pragmatic (Bulleit, 2017), thus assigning value based on utility. However, this is speculative given the lack of relevant data and needs further exploration.

\section{Limitations}

Although this study advances our understanding of the factors that influence BI and SRB among technology teachers, the following limitations should be noted. First, as a methodological limitation, although we discussed the differences between the PDP and NoPDP groups, the comparison was limited by the small sample size. This may be because our target population is very small in Taiwan, and we assume that $45 \%$ of technology teachers was sufficiently representative of the whole population in the current study. However, we still suggest conducting research with a larger participant sample to examine the relationships among the TTBIM. Such research might generate more findings with convincing evidence regarding the two theoretical models (Chao, 2012). Furthermore, our methodology would have benefitted from the analysis of model invariance (e.g., Cheng et al., 2015). Follow-up research examining differences in residuals, factor loadings, and variables between PDP and NoPDP groups could address this limitation.

This study also lacked follow-up data on teaching practices or student learning performance. Moreover, self-report data were obtained, which may not accurately reflect actual teaching performance. Further studies on technology teachers' BI to implement an engineering-focused curriculum are thus necessary. Students' learning performance with respect to the 


\section{Appendix 1}

Table 8 Questionnaire items addressing the latent variables

\section{Indicator Definition/Description}

Perceived ease of use (PEU): Teachers' perception of the practicability of the engineering-focused curriculum.

PEU1 I think that the engineering-focused courses in the Curriculum Guideline of the Technology Learning Field are easy to understand.

PEU2 I think that the engineering-focused courses in the Curriculum Guideline of the Technology Learning Field are easy to implement.

PEU3 I think that I can plan the delivery of the engineering-focused courses in the Curriculum Guideline of the Technology Learning Field.

PEU4 I think that I can develop appropriate engineering-focused teaching activities based on the Curriculum Guideline of the Technology Learning Field.

PEU5 I think that I can design appropriate engineering-focused learning assessments based on the Curriculum Guideline of the Technology Learning Field.

Perceived usefulness (PU): Teachers' perception of the value of engineering-focused curriculum.

PU1 I think that understanding basic engineering concepts is necessary for all citizens in the modern world.

PU2 I think that every student should complete basic engineering courses.

PU3 I think that engineering-focused courses should be compulsory in high school.

PU4 I think that schools should encourage interested students to take engineering-focused courses.

Beliefs (BF): Teachers' beliefs about teaching the engineering-focused curriculum.

BF1 I believe that engineering-focused courses help students apply scientific and mathematical principles.

BF2 I believe that engineering-focused courses help students develop problem-solving skills.

BF3 I believe that engineering-focused courses can help students understand the requirements of engineering-related careers.

Subjective norms (SN): Whether the positive or negative support given important reference groups affect the teaching of an engineering-focused curriculum.

SN1 I will teach engineering-focused courses because this is a requirement of the educational authorities (e.g., the Ministry of Education and county or city education department).

SN2 I will teach engineering-focused courses because this is a requirement of school administrators (e.g., principals, academic directors).

SN3 I will teach the engineering-focused courses because this is a requirement for joint lesson preparation with other teachers and tutors.

SN4 I will teach engineering-focused courses based on advertisements in mass media

(e.g., newspapers, magazines, television, internet).

Perceived behavioral control (PBC): The ability of teachers to adjust or apply resources to implement the engineering-focused curriculum.

PBC1 I can develop or tailor my teaching activities based on students' interest in engineering-focused courses.

PBC2 I can devise content for engineering-focused courses according to students' experiences in daily life.

PBC3 I can teach engineering-focused courses in collaboration with interdisciplinary teachers.

PBC4 I can teach engineering-focused courses involving student projects.

PBC5 I can teach students to apply relevant scientific and mathematical knowledge through engineering experiments.

PBC6 I can teach students engineering design skills through hands-on activities.

Behavioral intentions (BI): Teachers' behavioral intentions to implement the engineering-focused curriculum.

BI1 To implement the engineering-focused curriculum, I will participate in the PDP.

BI2 I am willing to implement the engineering-focused curriculum in my classes.

Bl3 I intend to plan my teaching based on the engineering-focused curriculum.

BI4 I intend to teach based on the engineering-focused curriculum.

BI5 I intend to design learning assessments based on the engineering-focused curriculum.

Self-reported behavior (SRB): The self-reported behavior of technology teachers in implementing an engineering-focused curriculum in their school.

SRB1 I have already participated in the PDP.

SRB2 I have already implemented the engineering-focused curriculum in my teaching.

SRB3 I have already planned my teaching based on the engineering-focused curriculum.

SRB4 I have already taught based on the engineering-focused curriculum.

SRB5 I have already designed student evaluations based on the engineering-focused curriculum. 


\section{Appendix 2}

Table 9 Descriptive statistics of the indicators

\begin{tabular}{llllllllllllll}
\hline Indicators & Minimum & Maximum & Mean & SD & Skewness & Kurtosis & Indicators & Minimum & Maximum & Mean & SD & Skewness & Kurtosis \\
\hline PEU1 & 1 & 5 & 3.78 & 1.044 & -0.689 & -0.219 & PBC1 & 2 & 5 & 4.22 & 0.774 & -0.688 & -0.125 \\
PEU2 & 1 & 5 & 3.26 & 1.034 & -0.256 & -0.632 & PBC2 & 2 & 5 & 4.08 & 0.794 & -0.543 & -0.197 \\
PEU3 & 1 & 5 & 3.76 & 0.919 & -0.671 & 0.495 & PBC3 & 1 & 5 & 3.86 & 0.952 & -1.004 & 1.175 \\
PEU4 & 1 & 5 & 3.78 & 0.901 & -0.792 & 0.807 & PBC4 & 2 & 5 & 4.19 & 0.789 & -0.882 & 0.624 \\
PEU5 & 1 & 5 & 3.63 & 0.935 & -0.473 & -0.273 & PBC5 & 2 & 5 & 4.03 & 0.805 & -0.558 & -0.072 \\
PU1 & 1 & 5 & 4.09 & 1.022 & -1.049 & 0.529 & PBC6 & 1 & 5 & 4.09 & 0.787 & -0.706 & 1.046 \\
PU2 & 1 & 5 & 4.14 & 0.985 & -1.031 & 0.374 & BI1 & 1 & 5 & 4.28 & 0.907 & -1.56 & 2.745 \\
PU3 & 1 & 5 & 4.07 & 1.034 & -1.153 & 0.953 & BI2 & 1 & 5 & 4.32 & 0.829 & -1.34 & 2.172 \\
PU4 & 2 & 5 & 4.45 & 0.696 & -1.278 & 1.773 & BI3 & 1 & 5 & 4.19 & 0.867 & -1.082 & 1.24 \\
BF1 & 2 & 5 & 4.36 & 0.798 & -0.997 & 0.125 & BI4 & 1 & 5 & 4.26 & 0.815 & -1.245 & 2.145 \\
BF2 & 2 & 5 & 4.43 & 0.739 & -1.053 & 0.244 & BI5 & 1 & 5 & 4.14 & 0.895 & -1.186 & 1.847 \\
BF3 & 2 & 5 & 4.46 & 0.712 & -1.133 & 0.614 & SR-U1 & 1 & 5 & 3.35 & 1.343 & -0.366 & -1.04 \\
SN1 & 1 & 5 & 4.07 & 0.89 & -0.886 & 0.686 & SR-U2 & 1 & 5 & 3.49 & 1.166 & -0.563 & -0.445 \\
SN2 & 1 & 5 & 3.96 & 0.922 & -0.749 & 0.267 & SR-U3 & 1 & 5 & 3.58 & 1.048 & -0.667 & -0.082 \\
SN3 & 1 & 5 & 4.04 & 0.922 & -1.001 & 1.167 & SR-U4 & 1 & 5 & 3.52 & 1.11 & -0.613 & -0.221 \\
SN4 & 1 & 5 & 3.78 & 0.958 & -0.354 & -0.464 & SR-U5 & 1 & 5 & 3.44 & 1.137 & -0.498 & -0.374 \\
\hline
\end{tabular}




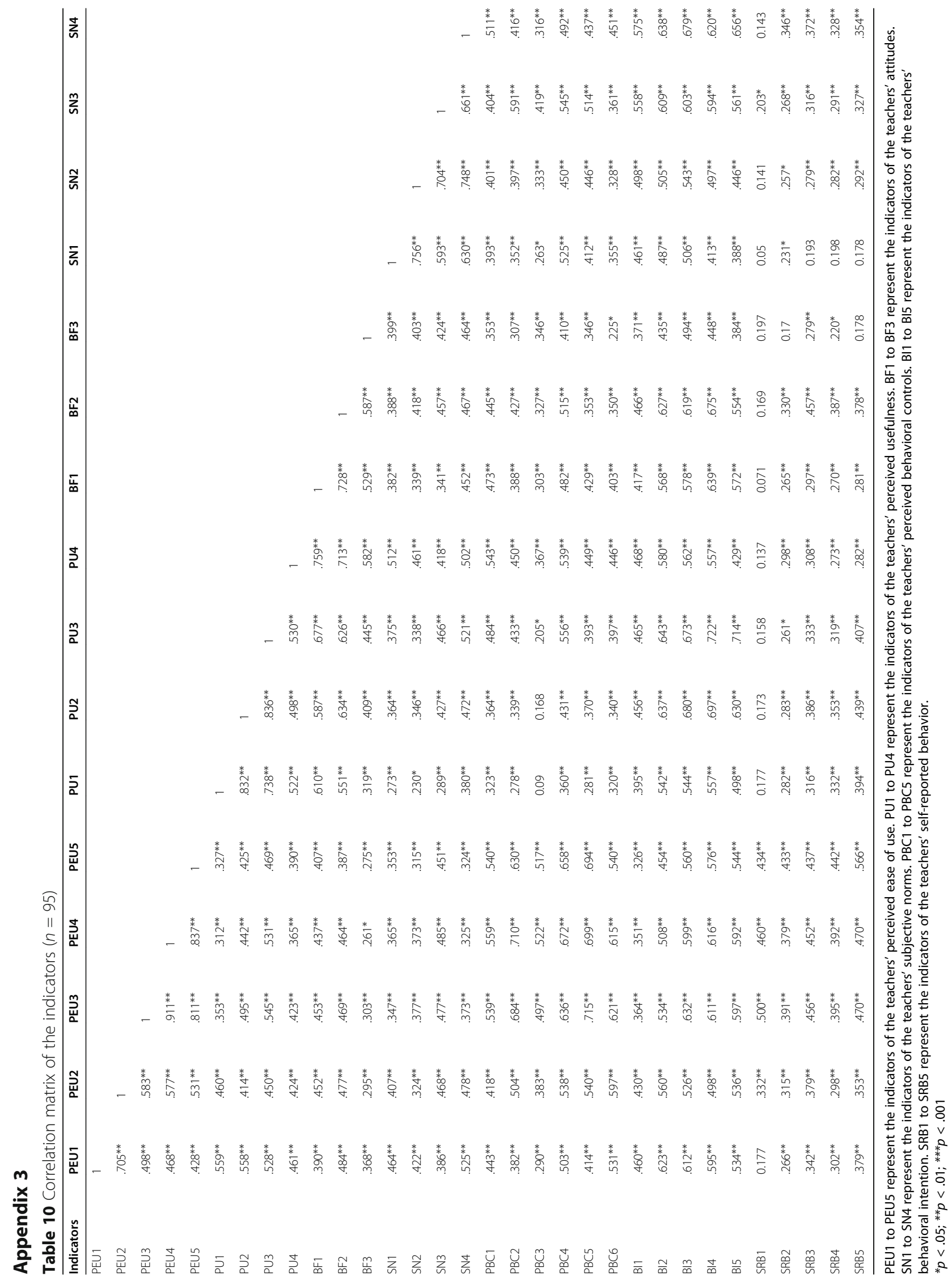




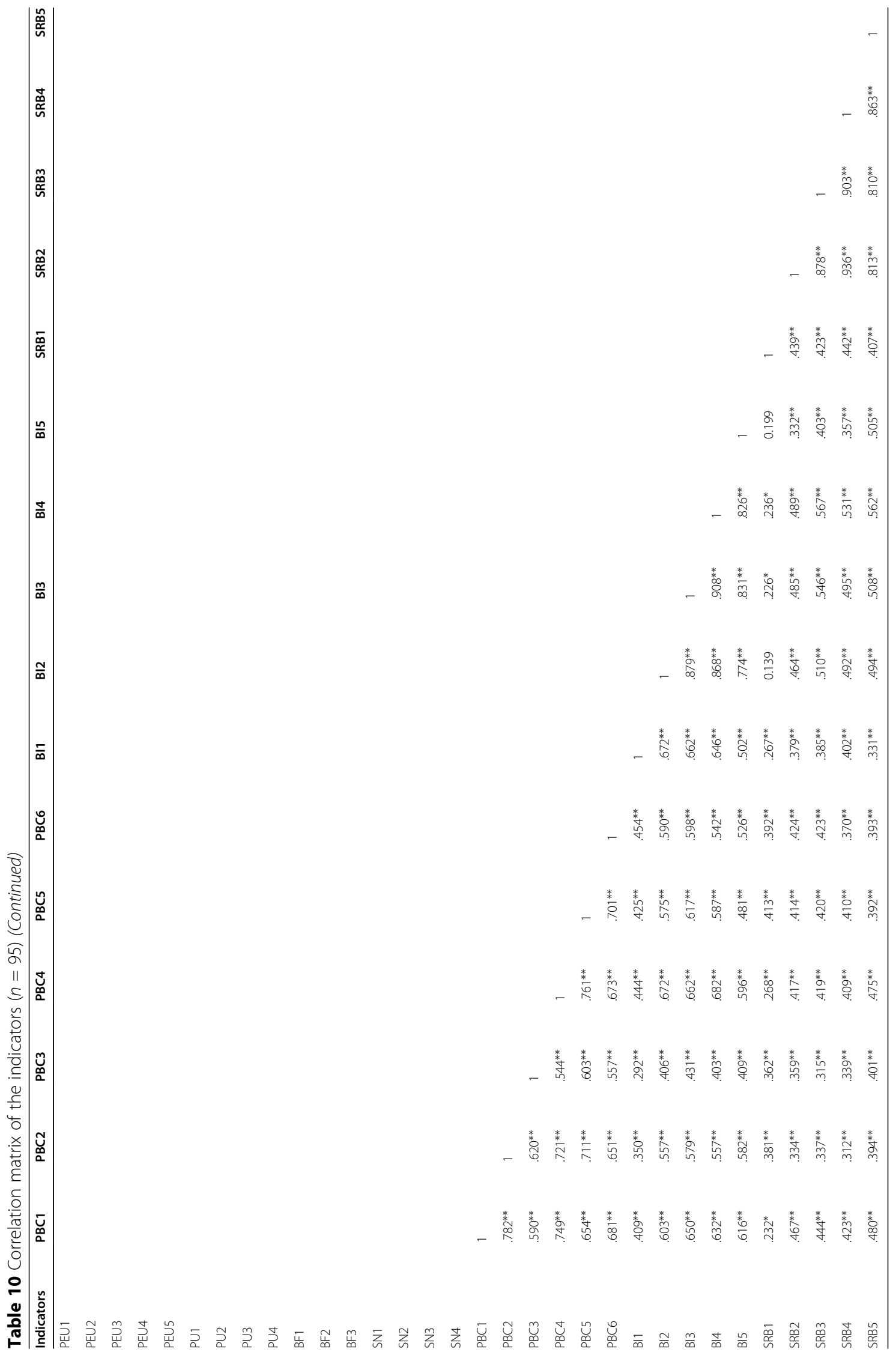




\section{Appendix 4}

Table 11 Validation of the 32 indicators $(n=95)$

Variable/indicators

PEU

PEU1

PEU2

PEU3

PEU4

PEU5

PU

PU1

PU2

PU3

PU4

$\mathrm{BF}$

BF1

BF2

BF3

SN

SN1

SN2

$\mathrm{SN} 3$

SN4

$\mathrm{PBC}$

PBC1

$\mathrm{PBC} 2$

$\mathrm{PBC} 3$

PBC4

PBC5

PBC6

BI

Bl1

BI2

BI3

B14

BI5

SRB

SRB1

SRB2

SRB3

SRB4
Cronbach's a

0.893(5) $)^{a}$

.

$0.890(4)^{a}$

$0.827(3)^{a}$

$0.895(4)^{\mathrm{a}}$

$0.920(6)^{a}$

$0.938(5)^{a}$

$\begin{array}{ll} & 0.956^{\mathrm{c}} \\ & 0.912 \\ 0.909(5)^{\mathrm{a}} & 0.906 \\ & 0.909 \\ & 0.929 \\ & 0.962(4)^{\mathrm{b}} \\ 0.962^{\mathrm{c}} \\ 0.863 \\ 0.870 \\ 0.858 \\ 0.877\end{array}$

Cronbach's a if indicator deleted $0.902(4)^{b}$

$0.902^{c}$

0.878

0.850

0.851

0.865

$0.923(3)^{b}$

0.833

0.812

0.831

$0.923^{c}$

$0.841(2)^{b}$

0.739

0.689

$0.841^{c}$

0.877

0.835

0.880

0.867

$0.924(5)^{b}$

0.901

0.899

$0.924^{c}$

0.901

0.901

0.907

$0.956(4)^{\mathrm{b}}$

$0.956^{c}$

0.906

.909

0.929

The numbers in parentheses show the number of indicators for each variable

${ }^{a}$ The value shows the initial reliability for each variable

${ }^{\mathrm{b}}$ The value shows the reliability of the variable after item deletion

'The indicators were deleted for better reliability 
engineering-focused curriculum should also be analyzed in the future according to specific teaching practices, perhaps using hierarchical linear modeling (e.g., the HLM in Kohnke et al., 2010).

\section{Abbreviations}

PDP: Professional development program; NoPDP: No participation in the professional development program; STEM: Science, Technology, Engineering, and Mathematics; TMOE: Taiwan Ministry of Education; CK: Content knowledge; PCK: Pedagogical content knowledge; Bl: Behavioral intentions; TPB: Theory of planned behavior; TTBIM: Technology teachers' behavioral intention model; SRB: Self-reported behaviors; PEU: Perceived ease of use; PU: Perceived usefulness; ATT: Attitude; SN: Subjective norms; PBC: Perceived behavioral control; CAD/CAM: Computer-aided design and manufacturing; CFA: Confirmatory factor analysis; CR: Composite reliability; AVE: Average variance extracted; RMSEA: Root mean square error of approximation; SRMR: Standardized root mean square residual; CFI: Comparative fit index; ML: Maximum likelihood

\section{Acknowledgements}

We are incredibly grateful to the teachers who participated in this study. We also appreciated that all reviewers and editors who provided precise comments make this study better.

\section{Authors' contributions}

$\mathrm{K}-\mathrm{CY}$ : Dr. Yu is the leader of this research, he is in charge of the research design, conducting questionnaire survey, data analysis, and writing the manuscript. (Contributions to this research: 30\%). P-HW: Dr. Wu is responsible for collecting and analyzing the related literature, analyzing the data, writing the manuscript. (Contributions to this research: 25\%). K-YL: Dr. Lin is responsible for research design, conducting questionnaire survey, and writing the manuscript. (Contributions to this research: 15\%). S-CF: Dr. Fan is responsible for research design, conducting questionnaire survey, providing comments to this research, and revised the manuscript. (Contributions to this research: 10\%). S-YT: Dr. Tzeng is responsible for analyzing the data, writing the manuscript, and providing comments to this research. (Contributions to this research: 10\%). C-JK: Ms. Ku is responsible for introducing the professional development programs for teaching an engineering-focused curriculum, and revised the manuscript. (Contributions to this research: 10\%). All authors read and approved the final manuscript.

\section{Funding}

This study was supported by the Ministry of Science and Technology in Taiwan under MOST 108-2511-H-003-058-MY4, and the "Institute for Research Excellence in Learning Sciences" of National Taiwan Normal University from The Featured Areas Research Center Program within the framework of the Higher Education Sprout Project by the Ministry of Education in Taiwan.

\section{Availability of data and materials}

Not applicable.

\section{Declarations}

Ethics approval and consent to participate

Ethical approval for this study was waived by Taiwan Centers for Disease Control Policy \# 1010265075 because this research is on investigating technology teachers' perceptions on implementing an engineering-focused curriculum and the research participants are all adults.

\section{Consent for publication}

Not applicable.

\section{Competing interests}

The authors declare that they have no competing interests.

\section{Author details}

'Department of Technology Application and Human Resource Development, National Taiwan Normal University, Taipei, Taiwan. ${ }^{2}$ Research Center for Testing and Assessment, National Academy for Educational Research, Taipei, Taiwan. ${ }^{3}$ Department of Technology Application and Human Resource Development and Institute for Research Excellence in Learning Sciences, National Taiwan Normal University, Taipei, Taiwan. ${ }^{4}$ Department of Industrial Technology Education, National Kaohsiung Normal University, Kaohsiung, Taiwan. ${ }^{5}$ Department of Graphic Communications and Digital Publishing, Shih-Hsin University, Taipei, Taiwan.

Received: 27 August 2020 Accepted: 14 July 2021

Published online: 28 July 2021

\section{References}

Agudo-Peregrina, Á. F., Hernández-García, Á., \& Pascual-Miguel, F. J. (2014). Behavioral intention, use behavior and the acceptance of electronic learning systems: Differences between higher education and lifelong learning. Computers in Human Behavior, 34, 301-314. https://doi.org/10.1016/j.chb.2013.10.035.

Ajzen, I. (1985). From intentions to actions: A theory of planned behavior. In J. K. Beckmann (Ed.), Action control: From cognition to behavior. Springer. https:// doi.org/10.1007/978-3-642-69746-3_2.

Ajzen, I. (1991). The theory of planned behavior. Organizational Behavior and Human Decision Processes, 50(2), 179-211. https://doi.org/10.1016/07495978(91)90020-T.

Anderson, J. C., \& Gerbing, D. W. (1988). Structural equation modeling in practice: A review and recommended two-step approach. Psychological Bulletin, 103(3), 411-423. https://doi.org/10.1037//0033-2909.103.3.411.

Bagozzi, R. P., \& Yi, Y. (1988). On the evaluation of structural equation models. Journal of the Academy of Marketing Science, 16(1), 74-94. https://doi.org/10.1 007/bf02723327.

Bentler, P. (1990). Comparative fit indices in structural models. Psychological Bulletin, 107(2), 238-246. https://doi.org/10.1037/0033-2909.107.2.238.

Bollen, K. A. (1989). Structural equations with latent variables. Wiley. https://doi. org/10.1002/9781118619179.

Bowen, N. K., \& Guo, S. (2011). Evaluating and improving CFA and general structural models. In N. K. Bowen, \& S. Guo (Eds.), Structural Equation Modeling (pp. 135-166). Oxford University Press. https://doi.org/10.1093/a cprof:oso/9780195367621.003.0006.

Bulleit, W. M. (2017). Pragmatism and engineering. In D. P. Michelfelder, B. Newberry, \& Q. Zhu (Eds.), Philosophy of engineering and technology: Exploring boundaries, expanding connections (Vol. vol 26, pp. 13-22). Cham: Springer Link: Springer. https://doi.org/10.1007/978-3-319-45193-0

Carpenter, T. P., Fennema, E., Peterson, P. L., Chiang, C.-P., \& Loef, M. (1989). Using knowledge of children's mathematics thinking in classroom teaching: An experimental study. American Educational Research Journal, 26(4), 499-531. https://doi.org/10.3102/00028312026004499.

Chao, Y.-L. (2012). Predicting people's environmental behaviour: theory of planned behaviour and model of responsible environmental behavior. Environmental Education Research, 18(4), 437-461. https://doi.org/10.1080/13 504622.2011.634970.

Chen, F., Curran, P. J., Bollen, K. A., Kirby, J., \& Paxton, P. (2008). An empirical evaluation of the use of fixed cutoff points in RMSEA test statistic in structural equation models. Sociological Methods \& Research, 36(4), 462-494. https://doi.org/10.1177/0049124108314720.

Cheng, S.-I., Chen, S.-C., \& Yen, D. C. (2015). Continuance intention of E-portfolio system: A confirmatory and multigroup invariance analysis of technology acceptance model. Computer Standards \& Interfaces, 42, 17-23. https://doi. org/10.1016/j.csi.2015.03.002.

Chien, S.-P., Wu, H.-K., \& Wu, P.-H. (2018). Teachers' beliefs about, attitudes toward, and intention to use technology-based assessments: A structural equation modeling approach. Eurasia journal of mathematics, science and technology education, 14(10), 228-244. https://doi.org/10.29333/ejmste/93379.

Christian, K. B., Kelly, A. M., \& Bugallo, M. F. (2021). NGSS-based teacher professional development to implement engineering practices in STEM instruction. International Journal of STEM Education, 8(1), 21-38. https://doi. org/10.1186/s40594-021-00284-1.

Comrey, A. L., \& Lee, H. B. (1992). A first course in factor analysis. Erlbaum.

Cronbach, L. J. (1951). Coefficient alpha and the internal structure of tests. Psychometrika, 16(3), 297-334. https://doi.org/10.1007/bf02310555. 
Darling-Hammond, L., \& Baratz-Snowden, J. (2007). A good teacher in every classroom: Preparing the highly qualified teachers our children deserve. Educational Horizons, 85(2), 111-132 www.jstor.org/stable/42926597.

Daugherty, J. L., \& Custer, R. L. (2012). Secondary level engineering professional development: Content, pedagogy, and challenges. International Journal of Technology and Design Education, 22(1), 51-64. https://doi.org/10.1007/s1 0798-010-9136-2.

Davis, F. D., Bagozzi, R. P., \& Warshaw, P. R. (1989). User acceptance of computer technology: A comparison of two theoretical models. Management science, 35(8), 982-1003. https://doi.org/10.1287/mnsc.35.8.982.

Eccles, J. S., Adler, T. F., Futterman, R., Goff, S. B., Kaczala, C. M., Meece, J. L., \& Midgley, C. (1983). Expectancies, values and academic behaviors. In J. T. Spence (Ed.), Achievement and Achievement Motives. San Francisco: W. H. Freeman and Company.

Fan, S. C., \& Yu, K. C. (2017. The development of new technology teacher education curriculum in Taiwan. Technology Education New Zealand (TENZ) / International Conference on Technology Education (ICTE) 2017 conference, Christchurch, New Zealand.

Fishbein, M., \& Ajzen, I. (1975). Belief, attitude, intention and behavior: An introduction to theory and research. Co: Addison-Wesley Pub.

Fornell, C. (1982). A second generation of multivariate analysis methods. Praeger.

Fornell, C., \& Larcker, D. F. (1981). Evaluating structural equation models with unobservable variables and measurement error. Journal of Marketing Research, 18(1), 39-50. https://doi.org/10.2307/3151312.

Hammack, R., \& Ivey, T. (2019). Elementary teachers' perceptions of K-5 engineering education and perceived barriers to implementation. Journal of Engineering Education, 108(4), 503-522. https://doi.org/10.1002/jee.20289.

Harrington, D. (2008). Confirmatory factor analysis. Oxford University Press. https:// doi.org/10.1093/acprof:oso/9780195339888.001.0001

Hynes, M. M. (2012). Middle-school teachers' understanding and teaching of the engineering design process: A look at subject matter and pedagogical content knowledge. International Journal of Technology and Design Education volume, 22(3), 345-360. https://doi.org/10.1007/s10798-010-9142-4.

Kaiser, F. G., Hübner, G., \& Bogner, F. X. (2015). Contrasting the theory of planned behavior with the value-belief-norm model in explaining conservation behavior. Journal of Applied Social Psychology, 35(10), 2150-2170. https://doi. org/10.1111/j.1559-1816.2005.tb02213.x.

Kirchhoff, A., \& Lawrenz, F. (2011). The use of grounded theory to investigate the role of teacher education on STEM teachers' career paths in high-need schools. Journal of Teacher Education, 62(3), 246-259. https://doi.org/10.1177/ 0022487110397840

Kline, R. B. (2011). Principles and practice of structural equation modeling, (3rd ed. ). New York: Guilford Publications.

Kohnke, O., Mueller, K., \& Wolf, T. (2010). A cross-national examination of the technology acceptance model. the annual conference of the Society of Industrial \& Organizational Psychology (SIOP), Atlanta.

Kriek, J., \& Stols, G. (2010). Teachers' beliefs and their intention to use interactive simulations in their classrooms. South African Journal of Education, 30(3), 439456. https://doi.org/10.15700/saje.v30n3a284.

Lin, K.-Y., \& Williams, P. J. (2016). Taiwanese Preservice Teachers' Science, Technology, Engineering, and Mathematics Teaching Intention. International Journal of Science and Mathematics Education, 14(6), 1021-1036. https://doi. org/10.1007/s10763-015-9645-2.

Lin, K.-Y., Wu, Y.-T., Hsu, Y.-T., \& Williams, P. J. (2021). Effects of infusing the engineering design process into STEM project-based learning to develop preservice technology teachers' engineering design thinking. International Journal of STEM Education, 8(1), 1-15. https://doi.org/10.1186/s40594-020-00258-9.

Margot, K. C., \& Kettler, T. (2019). Teachers' perception of STEM integration and education: A systematic literature review. International Journal of STEM Education, 6(2), 1-16. https://doi.org/10.1186/s40594-018-0151-2.

McLaughlin, M. W. (2002). Sites and sources of teachers' learning. In C. Sugrue, \& C. Day (Eds.), Developing teachers and teaching practice: International research perspectives (pp. 95-115). Taylor \& Francis, Inc.. https://doi.org/10.4324/97802 03166185_chapter_6.

Merrill, C., Custer, R. L., Daugherty, J., Westrick, M., \& Zeng, Y. (2008). Delivering core engineering concepts to secondary level students. Journal of technology education, 20(1), 48-64. https://doi.org/10.21061/jte.v20i1.a.4.

Monroe, M. C., Day, B. A., \& Grieser, M. (2000). GreenCOM weaves four strands. In B. A. Day \& M. C. Monroe (Eds.), Environmental education \& communication for a sustainable world: Handbook for international practitioners. Washington, DC: Academy for Educational Development.
Nathan, M. J., Tran, N. A., Atwood, A. K., Prevost, A., \& Phelps, L. A. (2010). Beliefs and expectations about engineering preparation exhibited by high school STEM teachers. Journal of Engineering Education, 99(4), 409-426. https://doi. org/10.1002/j.2168-9830.2010.tb01071.x.

National Research Council. (2009). Engineering in K-12 education: Understanding the status and improving the prospects. Washington, DC: National Academy Press.

NGSS Lead States. (2013). Next generation science standards: For states, by states. Washington, DC: National Academies Press.

Park, S., \& Oliver, J. S. (2008). Revisiting the conceptualisation of pedagogical content knowledge (PCK): PCK as a conceptual tool to understand teachers as professionals. Research in Science Education, 38(3), 261-284. https://doi. org/10.1007/s11165-007-9049-6.

Pynoo, B., \& van Braak, J. (2014). Predicting teachers' generative and receptive use of an educational portal by intention, attitude and self-reported use. Computers in Human Behavior, 34, 315-322. https://doi.org/10.1016/j.chb.2013.12.024.

Richardson, V. (1994). Teacher change and the staff development process: A case in reading instruction. New York: Teachers College Press.

Rohaan, E. J., Taconis, R., \& Jochems, W. M. G. (2010). Reviewing the relations between teachers' knowledge and pupils' attitude in the field of primary technology education. International Journal of Technology and Design Education, 20(1), 15. https://doi.org/10.1007/s10798-008-9055-7.

Schreiber, J. B., Nora, A., Stage, F. K., Barlow, E. A., \& King, J. (2006). Reporting structural equation modeling and confirmatory factor analysis results: $\mathrm{A}$ review. The Journal of Educational Research, 99(6), 323-338. https://doi.org/1 0.3200/joer.99.6.323-338.

Shulman, L. S. (1986). Those who understand: Knowledge growth in teaching. Educational Researcher, 15(2), 4-14. https://doi.org/10.3102/0013189X015002004.

Stein, S. J., Ginns, I. S., \& McDonald, C. V. (2007). Teachers learning about technology and technology education: Insights from a professional development experience. International Journal of Technology and Design Education, 17(2), 179-195. https://doi.org/10.1007/s10798-006-0008-8.

Taiwan Ministry of Education. (2016). Professional development programs for preservice teachers in technology domain. Taipei: National Academy for Educational Research.

Taiwan Ministry of Education. (2018). Curriculum guidelines of 12-year basic education: Technology Learning Field. Taipei: National Academy for Educational Research. https://www.naer.edu.tw/ezfiles/0/1000/img/67/1522 93419.pdf

Taylor, S., \& Todd, P. A. (1995). Understanding information technology usage: A test of competing models. Information Systems Research, 6(2), 144-176. https://doi.org/10.1287/isre.6.2.144.

Teo, T. (2011). Factors influencing teachers' intention to use technology: Model development and test. Computers \& Education, 57(4), 144-176. https://doi. org/10.1016/j.compedu.2011.06.008.

Thibaut, L., Knipprath, H., Dehaene, W., \& Depaepe, F. (2018). The influence of teachers' attitudes and school context on instructional practices in integrated STEM education. Teaching and Teacher Education, 71, 190-205. https://doi. org/10.1016/j.tate.2017.12.014

Van Haneghan, J. P., Pruet, S. A., Neal-Waltman, R., \& Harlan, J. M. (2015). Teacher beliefs about motivating and teaching students to carry out engineering design challenges: Some initial data. Journal of Pre-College Engineering Education Research (J-PEER), 5(2), 1-9. https://doi.org/10.7771/2157-9288.1097.

Westland, J. C. (2010). Lower bounds on sample size in structural equation modeling. Electronic Commerce Research and Applications, 9(6), 476-487. https://doi.org/10.1016/j.elerap.2010.07.003.

Williams, P. J. (2010). Technology education to engineering: A good move? The Journal of Technology Studies, 36(2), 10-19. https://doi.org/10.21061/jots.v3 6i2.a.2.

Yaşar, S., Baker, D., Robinson-Kurpius, S., Krause, S., \& Roberts, C. (2013). Development of a survey to assess K-12 teachers' perceptions of engineering and familiarity with teaching design, engineering, and technology. Journal of Engineering Education, 95(3), 205-216. https://doi.org/10.1002/j.2168-9830.2 006.tb00893.x.

Yoon, S. Y., Evans, M. G., \& Strobel, J. (2014). Validation of the teaching engineering self-efficacy scale for K-12 teachers: A structural equation modeling approach. Journal of Engineering Education, 103(3), 463-485. https://doi.org/0.1002/jee.20049. https://doi.org/10.1002/jee.20049.

\section{Publisher's Note}

Springer Nature remains neutral with regard to jurisdictional claims in published maps and institutional affiliations. 